REVISTA BRASILEIRA DE AGRICULTURA IRRIGADA

Revista Brasileira de Agricultura Irrigada

v.1, n.1, p.24-49, 2007

Fortaleza, CE, INOVAGRI -

http://www.inovagri.org.br Protocolo

$001.07-29 / 11 / 2007$

Aprovado em 09/12/2007

\section{Planejamento da Irrigação com Uso de Técnicas de Otimização}

\section{José Antônio Frizzone}

\section{INTRODUÇÃO}

A melhoria da eficiência da irrigação deve atender a uma análise holística das fases pelas quais se passa o processo. A aproximação holística, tão necessária para entender a agricultura irrigada, é incorporada através da consideração de todos os fatores que podem influenciar na forma como a água é usada, sejam eles técnicos, econômicos, políticos, sociais ou ambientais. A análise pode ser posteriormente refinada pela ponderação do impacto de cada fator que influencia no uso da água em uma dada situação (Burton, 1999).

Para entender o que acontece em um sistema de irrigação é necessário realizar análise de diagnóstico para identificar as causas e os efeitos. A complexidade e a natureza das especificidades locais constituem a grande dificuldade para a

Professor Titular do Departamento de Engenharia Rural, Escola Superior de Agricultura "Luiz de Queiroz", Universidade de São Paulo, C.P. 9, 13418-900, Piracicaba, São Paulo, Brasil. E-Mail: frizzone@carpa.ciagri.usp.br solução de muitos problemas potenciais na agricultura irrigada. Problemas e soluções são melhores tratados em um diagrama de árvore onde um dado problema pode ter, ao mesmo tempo, causa e efeito, isto é, um problema A é causado por um problema $\mathrm{B}$, e causa um problema C. O problema $\mathrm{C}$, por outro lado, causa um problema D. Assim, uma distribuição de água ineficiente pode ser causada por um calendário de irrigação inadequado e tem o efeito de proporcionar desuniformidade da produtividade das culturas. $\mathrm{O}$ uso de um calendário de irrigação inadequado pode ser causado por falta de treinamento dos irrigantes, pequeno nível de motivação, inadequada coleção de dados, etc. A identificação dos fatores envolvidos forma a base para um sistema hábil para a análise de diagnóstico.

Ao identificar soluções potenciais é importante investigar a exeqüibilidade daquelas soluções. Melhorar o manejo da irrigação e a operação dos sistemas através de treinamento só é possível se as pessoas envolvidas aplicarem o treinamento. Elas devem, portanto, ser motivadas e ter as facilidades necessárias.

A maior restrição para nosso entendimento sobre o uso da água é a dificuldade associada com sua medida e quantificação. Medições e registros de umidade do solo, vazão, pressão do sistema, variáveis de clima são raros e providos erros potenciais. A determinação correta quantidade de água requerida pela cultura em períodos específicos do seu desenvolvimento é difícil, se não impossível, para a maioria dos irrigantes. Sem a previsão da lâmina de irrigação definida como objetivo, é pouco provável que os agricultores apliquem a quantidade de água necessária. Dado o número e a natureza das variáveis que necessitam ser conhecidas (umidade do solo na capacidade de campo, conteúdo de água no solo em um dado momento, profundidade das raízes, vazão disponível, vazão aplicada, etc.) não é surpreendente que a eficiência de aplicação para a maioria dos irrigantes seja relativamente baixa - como poderia ser diferente? 
Questões que poderiam ser dirigidas a esse respeito são: como o irrigante poderia decidir quando e quanto irrigar? Como ele sabe quando aplicou suficiente quantidade de água? É eficiente a forma como o irrigante opera o sistema de irrigação em função da sua experiência? Seu nível educacional, seu conhecimento, o aconselhamento que ele procura são adequados?

$\mathrm{Na}$ formulação das metas para uso de água é conveniente re-analisar e considerar não só quanto a água é produtiva, mas sim qual a produtividade potencial está sendo perdida pelo manejo inadequado do recurso hídrico. Um exemplo clássico é a escassa atenção dada à perda produtiva potencial por falhas provenientes da falta de manutenção dos sistemas de irrigação. As perdas potenciais, ao longo dos anos, podem somar uma quantidade muitas vezes maior do que a quantidade de recursos financeiros necessários para a adequada manutenção do sistema. As perdas de produtividade potencial nos projetos de irrigação, decorrentes da manutenção inadequada, são pouco discutidas na literatura.

Estudos recentes sobre uso da água em sistemas de irrigação têm questionado a validade da preocupação com as baixas eficiências de condução e aplicação quando a água resultante da drenagem é re-usada à jusante do sistema. Então, a questão que surge é a seguinte: é mais conveniente focar o re-uso da água de drenagem em vez de focar a melhoria do manejo da água derivada à parcela e do sistema de irrigação?

Para melhorar o manejo da irrigação é necessário estabelecer procedimentos para a avaliação do desempenho dos sistemas. A teoria do manejo requer que os objetivos sejam identificados e definidos; as metas sejam fixadas, e as medidas e os indicadores de desempenho sejam usados para monitorar a consecução das metas e, por conseguinte, os objetivos. A inadequação de procedimentos para avaliação do desempenho foi identificada por pesquisadores nos meados dos anos 80, quando eles estudaram como os sistemas de irrigação estavam sendo manejados. Desde então muitos trabalhos de avaliação de desempenho foram conduzidos.
Ainda serão necessárias pesquisas para identificar medidas práticas para atender às demandas da avaliação de desempenho de diferentes tipos de sistemas de irrigação e de drenagem. A disseminação destas informações em um formato utilizável pelos técnicos da extensão rural e pelos irrigantes é crucial para proporcionar melhoria no manejo e uso da água.

A caracterização dos tipos de sistemas de irrigação está associada com as questões do desempenho. Se as soluções para o baixo desempenho estão sendo aplicadas a outros sistemas além daqueles para os quais as pesquisas foram conduzidas, é necessário um procedimento para descrever e categorizar os sistemas de forma que as soluções potenciais possam ser transferidas.

Uma das mais surpreendentes características do manejo dos projetos públicos de irrigação é a aceitação tácita de que pouco ou nada pode ser feito nos projetos de gestão governamental para relacionar salários e remuneração com desempenho dos projetos de irrigação. A crença de que os funcionários públicos não podem ser recompensados pelas suas ações e o desempenho de um projeto de irrigação é inerente, é que faz o Banco Mundial e outras agências de financiamento forçarem os governos a mudar ou privatizar os projetos de irrigação. Existe espaço para idéias inovadoras para sugerir formas para remunerar os técnicos de agências públicas visando um bom desempenho dos projetos, em vez de fechar os olhos e seguir corrupto e continuar com práticas injustas. Sob esse foco muitas oportunidades valiosas identificadas pela pesquisa podem falhar ao serem implementadas.

O grau de desenvolvimento que segue a agricultura irrigada em alguns países é uma valiosa oportunidade para acumular experiência. $\mathrm{O}$ desenvolvimento que tem acontecido em certos países, as razões e as aptidões ambientais para tal desenvolvimento, fornecem indicações para o desenvolvimento em outros países. Existe uma progressão natural dentro da sociedade para adaptar e refinar sua tecnologia de irrigação com base na sua própria história e no ambiente

R. Bras. Agric. Irrigada, v.1, n.1, p.24-49, 2007. 
político/técnico/econômico. Têm ocorrido aprimoramentos no sentido de melhorar a eficiência de uso da água e a conservação da energia (sistematização do terreno a laser para irrigação por superfície; irrigação por superfície com vazão intermitente; sistema de re-uso da água escoada no final da parcela; substituição de sistemas de irrigação menos eficientes por mais eficientes como microirrigação). Estes aprimoramentos têm seguido aproximações passo-a-passo e, enquanto as restrições têm sido atenuadas, novos desafios têm sido encontrados. É valioso observar a experiência de outros países na busca de modelos para o processo de desenvolvimento.

A avaliação do desempenho dos sistemas de irrigação necessita ser focada em três áreas: primeiramente, o entendimento sobre o que está acontecendo. Segundo, como as avaliações podem melhorar as práticas de manejo da irrigação e, terceiro, onde existe a necessidade de adoção de tecnologias, de práticas e de procedimentos para maior eficiência do uso de água. Dada a limitação na disponibilidade de recursos financeiros para os trabalhos de avaliação, atenção também precisa ser dada a quanto dos resultados serão úteis e aplicados e a extensão dos impactos obtidos. Serão necessárias avaliações sobre a probabilidade das técnicas de manejo serem adotadas e do potencial para contribuir positivamente com a redução do desperdício de água, com o aumento da produtividade e com o aumento da renda do irrigante.

Este texto procura apresentar técnicas de manejo da irrigação que proporcionam aumento da eficiência do uso da água e identificam estratégias para a otimização da irrigação, visando à maximização do lucro da atividade agrícola, à economia de água e à redução dos impactos ambientais decorrentes da irrigação. Trata-se da maximização do lucro na propriedade agrícola, o que representa um problema de otimização. Serão discutidas as características essenciais da otimização da irrigação focando algumas análises simples, que geralmente desconsideram muitas das complexidades da agricultura real, mas que poderão ilustrar a natureza essencial da otimização da irrigação.

\section{ENFOQUES DO MANEJO DA IRRIGAÇÃO}

O manejo racional da irrigação pressupõe o uso criterioso do recurso hídrico disponível para se maximizar a produtividade das culturas com o uso eficiente da água, da energia, dos fertilizantes e de outros insumos empregados na produção, considerando os aspectos sociais e ecológicos da região. Outros objetivos também podem ser estabelecidos, como maximizar a receita líquida por unidade de volume de água ou por unidade de área irrigada.

As práticas convencionais de irrigação baseiam-se na necessidade de água da cultura, definida pela demanda evapotranspirométrica, e na eficiência de aplicação de água. Para dar suporte à formulação de calendários de irrigação as pesquisas tem sido guiadas sob quatro enfoques de manejo da irrigação: irrigação total, irrigação suplementar, irrigação com déficit e irrigação de "salvação".

$\mathrm{Na}$ irrigação total, toda água necessária para atender a demanda evapotranspirométrica da cultura é proveniente da irrigação. Esse tipo de manejo é aplicado em regiões de clima árido ou semiárido, ou em regiões onde a precipitação é insignificante. $\mathrm{Na}$ irrigação suplementar, a água necessária ao atendimento da demanda evapotranspirométrica da cultura no intervalo entre duas irrigações consecutivas, é proveniente, em parte, da irrigação e, em parte, da precipitação pluviométrica efetiva. Nesse caso diz-se que a irrigação suplementará a precipitação efetiva no atendimento da demanda de água da cultura. $\mathrm{Na}$ irrigação com déficit, planeja-se atender somente uma fração da demanda de água da cultura por evapotranspiração. Esse tipo de manejo pode ser praticado com irrigação total e com irrigação suplementar. $O$ déficit de água pode ser imposto durante todo o ciclo da cultura ou somente nas fases não críticas ao déficit hídrico. Neste último caso, são 
possíveis menores reduções na produtividade da cultura. $\mathrm{Na}$ irrigação de salvação, $\mathrm{O}$ objetivo é irrigar somente num período relativamente curto ou num estádio do cultivo. Exemplo típico ocorre na irrigação da cana-de-açúcar, onde se aplica por irrigação, a vinhaça ou a água proveniente da lavagem da cana, em duas ou três aplicações de 30 a $60 \mathrm{~mm}$ por mês, após o plantio para cana planta, ou após os cortes para cana soca (Matiole, 1998, Bernardo, 2006). Esse tipo de manejo também tem sido utilizado na cultura do milho, no período do pré-pendoamento, e na cultura do feijão, antes da floração e na formação dos grãos, quando ocorre falta de chuvas nesses períodos.

São duas as estratégias para o planejamento da irrigação: (a) suprir totalmente a necessidade de água da cultura, em condições de irrigação total ou irrigação suplementar - atendimento pleno da demanda evapotranspirométrica da cultura, ou irrigação sem déficit, e (b) suprir parcialmente a necessidade de água da cultura, em condições de irrigação total ou suplementar atendimento parcial da demanda evapotranspirométrica da cultura, ou irrigação com déficit.

$\mathrm{Na}$ irrigação sem déficit, o objetivo é aplicar uma quantidade média de água, capaz de suprir totalmente o déficit hídrico e de proporcionar a máxima produção por unidade de área, evitando perda de produtividade ou de qualidade do produto por deficiência de água. Com esse objetivo fica implícito que a disponibilidade de água não é fator limitante da produção. Como a aplicação de água não é totalmente uniforme no espaço, o excesso de água poderá reduzir a produção da cultura pela redução da aeração do solo, por lixiviação de nutrientes e por doenças associadas a solos úmidos. Os níveis preconizados de eficiência técnica da irrigação planejada para satisfazer plenamente a demanda de água da cultura são aqueles possíveis de obter com um grau mínimo de adequação da irrigação de $90 \%$, para culturas de alto ou médio valor econômico, ou de $75 \%$ para culturas de baixo valor econômico (Cuenca, 1989). A irrigação convencional é, desse modo, definida em termos da quantidade de água a ser aplicada para evitar déficit hídrico em $90 \%$ ou $75 \%$ da área. Esses índices constituem, até hoje, os fundamentos da irrigação padrão em todo o mundo. $\mathrm{O}$ grau de adequação se refere à fração da área que deve receber água suficiente para evitar perdas de produtividade ou de qualidade do produto. A irrigação para atender plenamente a demanda de água da cultura é um problema relativamente simples e claramente definido, com o objetivo de maximizar a produção por unidade de área.

$\mathrm{Na}$ irrigação com déficit, o objetivo é maximizar a produção por unidade de volume de água aplicada (eficiência de uso da água = eficiência produtiva, atualmente denominada produtividade da água). Com esse objetivo, visa-se a aumentar a eficiência de uso da água e economizar água pelo aumento da eficiência de aplicação (eficiência técnica), redução das perdas de água e redução da eficiência de armazenagem (Phene, 1989), pressupondo-se que a disponibilidade de água constitui limitação à produção agrícola e que o manejo da irrigação deve priorizar a minimização das perdas de água. Se a lâmina de irrigação for menor que a evapotranspiração da cultura no período (irrigação com déficit), o grau de adequação será reduzido, as produtividades serão menores, mas, como resultado, reduz-se a percolação, aumenta-se a eficiência de aplicação e há redução nos custos operacionais da irrigação e redução da lixiviação de produtos químicos.

Uma mudança fundamental deverá ocorrer no manejo da irrigação nos próximos anos, em decorrência das pressões econômicas sobre os agricultores, da crescente competição pelo uso da água e dos impactos ambientais da irrigação. Tais fatores motivarão uma mudança de paradigma da irrigação, enfocando-se, além da eficiência técnica/produtiva, a eficiência econômica. Esse novo enfoque pode ser descrito simplesmente como "otimização" e o argumento é que a mudança é fundamental, desejável e inevitável e será um avanço significativo nas práticas atuais, já que uma produção eficiente e rentável deve constituir o principal objetivo econômico de uma

R. Bras. Agric. Irrigada, v.1, n.1, p.24-49, 2007. 
empresa agrícola. A otimização da irrigação considera explicitamente os custos e os lucros, porém, maximizar a lucratividade é um problema substancialmente mais complexo e desafiador. Identificar estratégias ótimas de irrigação necessitará de modelos detalhados das relações água-cultura e eficiência de irrigação. Fatores econômicos, como custos de produção, preços do produto, custos de oportunidade da água, deverão ser explicitamente incorporados nas análises.

A otimização da irrigação não deve ser confundida aqui com o manejo da água na parcela, ou com o monitoramento sistemático da umidade do solo ou do estado hídrico da cultura para se determinar quando e quanto irrigar. Isso não quer dizer, entretanto, que este monitoramento não seja parte do enfoque de otimização. Pelo contrário, novas e mais sofisticadas técnicas de monitoramento da irrigação serão necessárias para implementar planos ótimos de irrigação.

\section{OTIMIZAÇÃO DA IRRIGAÇÃO PARA UMA CULTURA}

Uma irrigação ótima implica menores lâminas aplicadas em relação à irrigação plena, com conseqüente redução da produtividade da cultura, porém com algumas vantagens significativas. Os benefícios potenciais da irrigação com déficit advêm de três fatores: aumento da eficiência de irrigação; redução dos custos da irrigação e redução dos riscos associados aos impactos ambientais adversos da irrigação plena.

Muitos pesquisadores analisaram os benefícios econômicos da irrigação ótima em circunstâncias específicas e concluíram que a técnica pode aumentar a receita líquida proporcionada pelas culturas irrigadas (Stewart; Hagan; Pruitt, 1974; English; Nuss, 1982; Frizzone, 1986; English; Nakamura, 1989; Martin; Brocklin; Wilnes, 1989; English, 1990; Frizzone et al., 1995; Frizzone et al., 1997; Calheiros et al., 1996; Queiroz et al., 1996; Sousa; Frizzone; Peres, 1998; Heinemann et al., 2000; Andrade Júnior et al., 2001; Heinemann; Souza; Frizzone, 2001;
Frizzone et al., 2001; Paz et al., 2002; English; Solomon; Hoffman, 2002).

Embora a otimização da irrigação tenha sido tema de pesquisa por mais de quatro décadas, nenhum procedimento ótimo, sistemático e rigoroso está sendo usado na agricultura produtiva atualmente. English; Solomon e Hoffman (2002) citam uma revisão de literatura sobre esse tema, apontando muitos artigos baseados em teorias, mas não citam exemplos de otimização sistemática em condições de campo. Apresentam uma pesquisa informal com 42 profissionais-chave em irrigação, perguntando aos entrevistados se eles estavam conscientes de qualquer aplicação sistemática dos princípios da otimização em áreas de produção agrícola. A conclusão foi que nenhum podia citar qualquer exemplo de estratégia de otimização com base científica rigorosa, em nenhuma parte do mundo, apesar de muitos relatarem algumas estratégias intuitivas visualizadas por algum produtor.

Uma revisão dos livros-textos de irrigação mais comuns mostra que sempre é recomendado o dimensionamento formal da irrigação para a máxima produtividade das culturas. Alguns textos recomendam que o sistema de irrigação deverá aplicar a quantidade de água necessária para satisfazer a demanda total da cultura (James, 1988; American Society Of Civil Engineers, 1990). Em outros textos o procedimento é baseado na máxima depleção admissível de água no solo e, embora o nível de depleção seja escolhido pelo projetista, sempre implica irrigação plena (Keller; Bliesner, 1990; Bernardo, 1995). Apenas um dos textos revisados (Cuenca, 1989) sugere que sob algumas circunstâncias pode ser permitida maior depleção de água no solo, resultando na diminuição da produtividade e no aumento da lucratividade, em relação aos maiores custos da irrigação plena. Entretanto o autor chama a atenção para o fato de que tal prática poderá aumentar o risco de uma grande redução da produtividade, devido às inesperadas falhas do equipamento de irrigação ou à ocorrência de condições climáticas adversas.

R. Bras. Agric. Irrigada, v.1, n.1, p.3-11, 2007. 
A aparente relutância para explorar completamente o conceito de irrigação ótima em um contexto formal, nos livros-texto, deve-se possivelmente à crença de que os benefícios dessa técnica podem não justificar os riscos associados.

\section{Funções de produção, custos e receitas}

Para desenvolver estratégias ótimas de irrigação, é necessário utilizar relações entre a água aplicada e a produtividade, denominadas funções de produção águacultura (Frizzone, 1998). Tais funções deveriam basear-se na evapotranspiração (ET), em vez de relacionar a produtividade com a água aplicada, porque seriam mais independentes do sistema de irrigação, do solo e de outros fatores locais que influenciam a forma da curva. Mas, na prática, os irrigantes controlam a lâmina aplicada e não a ET. Para baixos níveis de irrigação, inferiores a cerca de $50 \%$ da irrigação plena, a produção tende a variar linearmente com a água aplicada (Vaux Jr.; Pruitt, 1983; Hargreaves; Samani, 1984). Além desse ponto, a relação torna-se curvilínea com o aumento da quantidade de água aplicada, como consequiência das perdas por percolação profunda, por escoamento superficial e por evaporação, até atingir um máximo. Para quantidades de irrigação superiores a esse ponto de máxima produção, ocorre um decaimento da curva, refletindo a diminuição da produtividade, em decorrência das condições anaeróbicas nas raízes, de doenças e de lixiviação de nutrientes associadas ao uso excessivo de água.

A irrigação necessária é geralmente definida como a quantidade de água requerida para atingir pleno potencial produtivo. Mas, devido à variabilidade espacial do solo e da água aplicada, não é possível irrigar toda a área com perfeita uniformidade $\mathrm{e}$, conseqüentemente, não é factível atingir o pleno potencial produtivo em cada ponto da área cultivada. Assim, para os objetivos das análises aqui desenvolvidas, deve-se interpretar irrigação plena como a lâmina de água aplicada $\left(\mathrm{w}_{\mathrm{m}}\right)$ capaz de proporcionar a maior produtividade média.

Sendo $\mathrm{y}(\mathrm{w})$ a função de produção água-cultura, em que y indica a produção por unidade de área $\left(\mathrm{kg} \cdot \mathrm{ha}^{-1}\right)$ e w a lâmina de água aplicada (mm), qual nível de água aplicada constituiria a irrigação plena? Se o objetivo é maximizar a produção por unidade de área, é necessário apenas igualar a zero a primeira derivada da função de produção, em relação à lâmina de água, e resolver para w. Assim, o objetivo da irrigação plena é definido por:

$$
\frac{\partial y(w)}{\partial w}=0
$$

Assumindo que a água é o único fator variável e que a função de produção águacultura é um polinômio do segundo grau (equação 2), tem-se:

$$
\begin{aligned}
& y(w)=r_{0}+r_{1} w+r_{2} w^{2} \\
& \frac{d y(w)}{d w}=r_{1}+2 r_{2} w=0 \\
& w_{m}=-\frac{r_{1}}{2 r_{2}} \\
& y\left(w_{m}\right)=r_{0}-\frac{r_{1}^{2}}{4 r_{2}}
\end{aligned}
$$

A receita bruta da unidade técnica é igual à produção da cultura multiplicada pelo preço do produto. Assim, as funções de produção água-cultura e de receita bruta têm a mesma forma geral. Portanto a quantidade de água que maximiza a produção por unidade de área $\left(\mathrm{w}_{\mathrm{m}}\right)$ também maximiza a receita bruta. Neste ponto, a eficiência marginal da utilização de água é zero, uma vez que a aplicação de um volume adicional de água não produz acréscimo na produção.

Sendo a quantidade de água aplicada inferior a $w_{m}$, a eficiência marginal de um incremento de água será maior que zero porque produzirá um certo incremento de produção. A eficiência marginal da água aumenta enquanto a quantidade de água aplicada diminui. Dessa forma, a irrigação parcial aumenta a eficiência do uso da água. 
A função de receita bruta para a unidade técnica pode ser expressa como:

$$
\mathrm{lb}(\mathrm{w})=\mathrm{p} \mathrm{y}(\mathrm{w})
$$

sendo: $\mathrm{Ib}(\mathrm{w})$ - receita bruta da unidade técnica por unidade de área, $\$ \mathrm{ha}^{-1} ; \mathrm{p}$ - preço unitário do produto da unidade técnica, $\$ \mathrm{~kg}^{-1}$; y (w) - produtividade da cultura em função da quantidade de água, $\mathrm{kg} \mathrm{ha}^{-1}$.

A relação entre a quantidade de água aplicada e o custo total de produção denomina-se função de custo e pode ser representada por uma linha reta, possuindo três importantes características. A primeira é o intercepto com a ordenada, associado aos custos fixos anuais de produção (custos de capital, taxas, seguros e outros custos fixos da irrigação, bem como custos fixos de preparo do solo, plantio, cultivo, uso de defensivos, fertilizantes e colheita). A segunda é a declividade, que representa os custos marginais variáveis da produção, incluindo os custos variáveis da irrigação (custos de bombeamento, de mão-de-obra envolvida na irrigação e de manutenção). Alguns custos podem variar indiretamente com a irrigação, uma vez que a produção varia com a quantidade de água aplicada. Por exemplo, um agricultor pode ajustar o uso de fertilizantes a uma expectativa de produtividade da cultura, que depende também da quantidade de água aplicada; os custos de colheita podem variar com a produtividade, e assim por diante. Todos esses fatores estão incorporados na declividade da função de custo. A terceira característica da função de custo é o seu limite superior, representando a capacidade do sistema, que define a máxima capacidade de derivação de água do sistema.

Embora a função de custo esteja representada por uma reta, no caso geral, ela pode ser curvilínea, especialmente quando se consideram os custos associados ao excesso de água aplicada, como custos da remoção do excesso de água e custos dos nutrientes percolados ou perdidos por escoamento superficial. Assumindo que é razoável utilizar uma função de custo linear para a unidade técnica (Hart; Norum; Peri, 1980; English, 1990), tem-se:

$$
c(w)=c_{0}+h(w)+c_{w} w
$$

sendo: $c(w)$ - custo total de produção por unidade de área da unidade técnica, $\$ \mathrm{ha}^{-1}$; $\mathrm{c}_{0}$ - custos fixos de produção por unidade de área, $\$ \mathrm{ha}^{-1} ; \mathrm{h}(\mathrm{w})$ - custos que dependem indiretamente da quantidade de água aplicada, $\$ \mathrm{ha}^{-1} ; \mathrm{c}_{\mathrm{w}}$ - custos que dependem diretamente da quantidade de água aplicada, \$ $\mathrm{m}^{-3}$, e $\mathrm{w}$ - volume de água aplicada por unidade de área, $\mathrm{m}^{3} \mathrm{ha}^{-1}$.

Assumindo, como condição simplificativa, que a soma dos custos fixos $\left(\mathrm{c}_{0}\right)$ e dos custos indiretamente dependentes da quantidade de água aplicada $[\mathrm{h}(\mathrm{w})]$ são constantes $\left(\mathrm{c}_{\mathrm{f}}\right)$, conforme sugerido por Hart; Norum e Peri (1980) e Frizzone (1998), podese expressar a função de custo total de produção da seguinte forma:

$$
c(w)=c_{f}+c_{w} w
$$

Algumas análises de custo consideram somente os custos diretos da irrigação e não levam em conta os outros custos da produção. Essa análise incompleta conduz a uma sub-estimativa do valor ótimo do déficit de irrigação e do ganho na receita líquida. Deve-se salientar que a redução na quantidade de água aplicada e a conseqüente redução na produção não implicam somente a redução dos custos da irrigação, mas também a redução nos custos de fertilizantes, de colheita e outros fatores da produção, e pode ainda implicar a redução dos custos de capital envolvidos na derivação de água e nos sistemas de irrigação.

English e Nuss (1982) analisaram a economia potencial de custos que pode ser atingida por um projeto de irrigação especificamente dimensionado para a irrigação com déficit em uma cultura de trigo. A análise foi desmembrada em três categorias: (1) redução nos custos de irrigação (energia, manutenção e mão-deobra) - $37 \%$ de economia; (2) redução nos custos fixos (custos de capital) - 36\% de

R. Bras. Agric. Irrigada, v.1, n.1, p.3-11, 2007. 
economia; (3) redução em outros custos de produção (tratos culturais, aplicações químicas, colheita) $-27 \%$ de economia.

A função de receita líquida da unidade técnica para a fazenda, com área irrigada $\mathrm{x}$, pode ser expressa da seguinte forma:

$$
Z(w)=x\left[p y(w)-c_{0}-h(w)-c_{w} w\right]
$$

ou,

$$
Z(w)=x\left[p y(w)-c_{f}-c_{w} w\right]
$$

\section{Maximização da receita líquida com restrição de terra}

Frizzone (1986) apresentou uma aproximação analítica para otimizar a irrigação. Utilizou uma função de receita líquida por unidade de área e determinou a lâmina de água que maximiza $\mathrm{Z}(\mathrm{w})$, isto é, o objetivo foi: $\mathrm{dZ}(\mathrm{w}) / \mathrm{dw}=0$. Esta derivada resulta em $\mathrm{dy}(\mathrm{w}) / \mathrm{dw}=\mathrm{c}_{\mathrm{w}} / \mathrm{p}$, significando que, sendo a água o único fator variável, a receita líquida por unidade de área se maximiza quando o produto físico marginal da água $(\mathrm{dy} / \mathrm{dw})$ for igual à relação de preços entre fator e produto $\left(\mathrm{c}_{\mathrm{w}} / \mathrm{p}\right)$.

A receita líquida é maximizada para uma lâmina de água $\mathrm{w}^{*}$, inferior a $\mathrm{w}_{\mathrm{m}}$ (irrigação plena). Neste ponto, a declividade da reta de custo é igual à declividade da curva de receita bruta. Para uma quantidade de água maior que $\mathrm{w}^{*}$, a reta de custo tem uma declividade maior que a curva de receita bruta, uma vez que os custos totais são aumentados em uma proporção maior que a receita bruta.

No intervalo entre $\mathrm{w}^{*} \mathrm{e} \quad \mathrm{w}_{\mathrm{m}}, \mathrm{o}$ fazendeiro pode se beneficiar da redução de custos. Além disso, uma decisão para utilizar menor quantidade de água pode possibilitar uma redução de capital e de outros custos fixos. Considerando que a disponibilidade de terra é o único fator limitante da produção, a estratégia ótima de irrigação é aplicar a lâmina de água que maximiza a receita líquida por unidade de área. Para explicitar a restrição de terra e o preço sombra do recurso, Frizzone (1998) utilizou o processo de otimização com operadores de Lagrange. Assim, o objetivo da fazenda e a restrição de terra podem ser expressos, matematicamente, da seguinte forma:

$$
\max Z(w)=x\left[p y(w)-c_{0}-h(w)-c_{w} w\right]
$$

ou,

$$
\max Z(w)=x\left[p y(w)-c_{f}-c_{w} w\right]
$$

sujeito a:

$$
g=x-\bar{x}=0
$$

sendo $\mathrm{g}$ a função de restrição de terra, $\mathrm{x}$ a área irrigada $\mathrm{e} \overline{\mathrm{x}}$ a área disponível para $\mathrm{o}$ cultivo.

Aplicando-se operadores de Lagrange (L) para otimizar a função-objetivo com restrição de terra, tem-se:

$$
L(x, w, \lambda)=x\left[y(w) \cdot p-c_{0}-h(w)-c_{w} w\right]-\lambda(x-\bar{x})
$$

A condição de ótimo é obtida igualando-se a zero as derivadas parciais da função lagrangeana, em relação a $w$, x e $\lambda$ :

$$
\begin{aligned}
& \frac{\partial L}{\partial w}=x\left(\frac{d y}{d w} p-\frac{d h}{d w}-c_{w}\right)=0 \\
& \frac{\partial L}{\partial x}=y(w) p-c_{0}-h(w)-c_{w} w-\lambda=0 \\
& \frac{\partial L}{\partial \lambda}=-x+\bar{x}=0
\end{aligned}
$$

em que ( $p d y / d w)$ é o valor do produto marginal da água; (dh/dw) é o custo marginal dos fatores que dependem indiretamente da água e (pdy/dw - dh/dw) é o valor líquido do produto marginal da água.

A equação (15) indica que, no ponto ótimo, o valor líquido do produto marginal da água deverá ser igual ao custo da água. A equação (16) indica que o valor marginal da terra $\lambda=\partial \mathrm{L} / \partial \mathrm{x}$ é igual à receita líquida por unidade de área, a qual é determinada pela

R. Bras. Agric. Irrigada, v.1, n.1, p.24-49, 2007. 
quantidade de água, pelo preço do produto e pelos custos de produção.

A máxima produção física só é justificada quando $\mathrm{h}(\mathrm{w})=0(\mathrm{ou} \mathrm{dh} / \mathrm{dw}=0) \mathrm{e}$ a água é livre $\left(\mathrm{c}_{\mathrm{w}}=0\right)$; caso contrário, a quantidade de água aplicada por unidade de área é uma função decrescente de $\mathrm{c}_{\mathrm{w}}$.

Sendo o objetivo da fazenda expresso pela equação (12) e a disponibilidade de terra o único fator limitante da produção, obtém-se de $\partial L / \partial w$ a seguinte relação:

$$
\frac{d y}{d w} p=c_{w}
$$

significando que a quantidade ótima de água $\left(\mathrm{w}^{*}\right)$, para a qual a receita líquida por unidade de área é maximizada, corresponde ao ponto em que o valor do produto marginal da água [(dy/dw) p] se iguala ao seu custo marginal $\left[\mathrm{c}_{\mathrm{w}}=\mathrm{dc}(\mathrm{w}) / \mathrm{dw}\right]$. A equação (18) indica que, no ponto ótimo, a derivada da função de produção será positiva e diferente de zero, ou seja, o ponto de máximo lucro será encontrado na porção ascendente da curva de produção. Assim, uma estratégia de maximização de lucro permitirá usar menos água por unidade de área que a de maximização da produção. Considerando uma função de produção água-cultura na forma de um polinômio do segundo grau (equação 2) e aplicando-se a equação (18), resulta:

$$
\begin{aligned}
& r_{1}+2 r_{2} w=\frac{c_{w}}{p} \\
& w^{*}=\frac{c_{w}-p r_{1}}{2 r_{2} p}
\end{aligned}
$$

Obtém-se o preço sombra da terra, que é uma medida do custo de oportunidade, pela derivada $\lambda=\partial \mathrm{L} / \partial \mathrm{x}$, fazendo-se $\mathrm{w}=\mathrm{w}^{*}$ e $y(w)=y\left(w^{*}\right)$ :

$$
\lambda=\left(r_{0}+r_{1} w^{*}+r_{2} w^{* 2}\right) p-c_{f}-c_{w} w^{*}
$$

A quantidade ótima de água representa apenas um ponto sobre a curva de produção, tendo pouco significado prático. É possível definir um intervalo de lâmina de irrigação no qual a receita líquida é maior que a obtida com irrigação para máxima produção. Conforme se observa na Figura 1, existe um intervalo de lâmina de água onde a irrigação com déficit é mais rentável que a irrigação plena, tendo-se como limite inferior um valor $\mathrm{w}_{\mathrm{el}}$, que resulta numa receita líquida equivalente àquela produzida por uma quantidade de água $\mathrm{w}_{\mathrm{m}}$.

No intervalo entre $\mathrm{w}_{\mathrm{m}}$ e $\mathrm{w}_{\mathrm{el}}$, a irrigação com déficit é mais rentável que a irrigação plena, para o caso em que a disponibilidade de terra é o fator limitante da produção. A amplitude desse intervalo indica o grau de segurança no manejo da irrigação com déficit. Se o intervalo é relativamente amplo, o risco associado à decisão pode ser pequeno. Um intervalo pequeno representa maior risco e implica maior cuidado no manejo da irrigação. $\mathrm{O}$ valor ótimo, nesse intervalo, é w*, definido pela equação (20). Qualquer quantidade de água entre $\mathrm{w}_{\mathrm{el}} \mathrm{e}_{\mathrm{m}}$ produzirá uma receita líquida, por unidade de área, maior que a obtida pela irrigação plena. $\mathrm{O}$ valor de $\mathrm{w}_{\mathrm{el}}$, para o qual a receita líquida é igual àquela que se consegue com $\mathrm{w}_{\mathrm{m}}$, é obtido pela solução do seguinte conjunto de equações:

$$
\begin{aligned}
& Z\left(w_{e l}\right)=x\left[p y\left(w_{e l}\right)-c_{f}-c_{w} w_{e l}\right] \\
& Z\left(w_{m}\right)=x\left[p y\left(w_{m}\right)-c_{f}-c_{w} w_{m}\right]
\end{aligned}
$$

Substituindo $\mathrm{y}\left(\mathrm{w}_{\mathrm{m}}\right)$ e $\mathrm{y}\left(\mathrm{w}_{\mathrm{el}}\right)$ nas equações (22) e (23), a quantidade de água $\mathrm{w}_{\mathrm{el}}$ é encontrada para $\mathrm{Z}\left(\mathrm{w}_{\mathrm{el}}\right)=\mathrm{Z}\left(\mathrm{w}_{\mathrm{m}}\right)$, o que resulta em:

$$
\begin{aligned}
& p r_{2} w_{e l}^{2}+\left(p r_{1}-c_{w}\right) w_{e l}+\left(\frac{p r_{1}^{2}}{4 r_{2}}-\frac{c_{w} r_{1}}{2 r_{2}}\right)=0 \\
& w_{e l}=\frac{-b+\sqrt{b^{2}-4 a c}}{2 a} \\
& \text { sendo: } \\
& a=p r_{2} \\
& b=p r_{1}-c_{w} \\
& c=\frac{p r_{1}^{2}}{4 r_{2}}-\frac{c_{w} r_{1}}{2 r_{2}}
\end{aligned}
$$


Aplicação 1: Para esta aplicação, utilizou-se uma função de produção para a cultura do feijoeiro, cultivar carioca (Figura 2), obtida por Figuerêdo et al. (1998), no Centro de Pesquisa Agropecuária dos Cerrados, Brasília - DF, durante três anos de experimentação em campo (1988, 1990 e 1991). A máxima produção física estimada $(3031,8 \mathrm{~kg}$ ha-1) ocorre para uma lâmina total de água de 573 $\mathrm{mm}$.

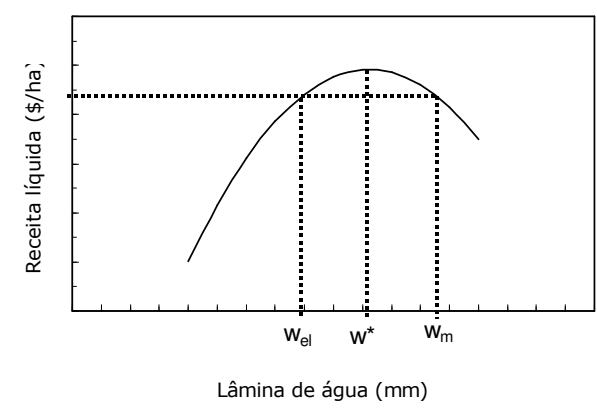

Figura 1 - Intervalo para o manejo racional da irrigação com déficit, quando a disponibilidade de terra é fator limitante da produção

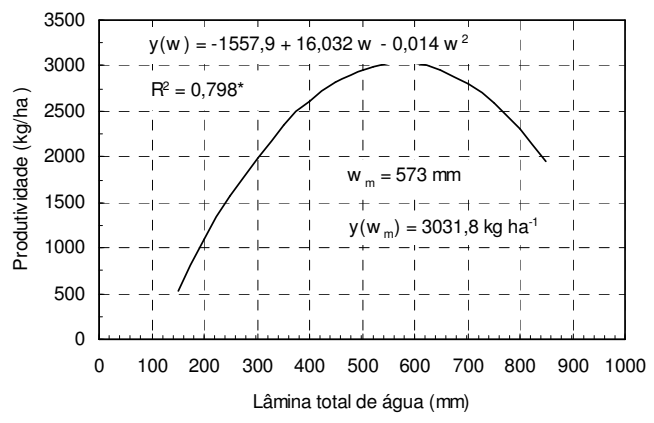

Figura 2 - Função de produção do feijoeiro, cultivar carioca, obtida por Figuerêdo et al. (1998), no CPAC, Brasília-DF, para a média dos anos de 1988, 1990 e 1991.

Nessa aplicação, utilizam-se os valores de preços e os custos de produção do feijoeiro, relatados por Frizzone (1995), para a região de Guaíra (SP), com sistema de irrigação por pivô central. No período de janeiro a dezembro de 1993, os preços reais da venda do feijão variaram de US\$21,07 a US\$ 41,28 por saca de $60 \mathrm{~kg}$, com média de US $\$ 31,51$. Os custos variáveis diretamente dependentes da quantidade de água aplicada variaram entre US\$0,32 e US\$0,74 $\mathrm{mm}^{-1} \mathrm{ha}^{-1}$, com média de US\$0,50 $\mathrm{mm}^{-1} \mathrm{ha}^{-1}$. O custo médio de produção, excetuando-se a irrigação, foi US $\$ 420 \mathrm{ha}^{-1}$. Para valores de $\mathrm{c}_{\mathrm{f}}$ $=$ US\$420 ha ${ }^{-1}, c_{\mathrm{w}}=\mathrm{US} \$ 0,74 \mathrm{~mm}^{-1} \mathrm{ha}^{-1} \mathrm{e} \mathrm{p}=$ US $\$ 0,5 \mathrm{~kg}^{-1}$, obtiveram-se $\mathrm{w}^{*}=520 \mathrm{~mm} \mathrm{e}$ $\mathrm{z}\left(\mathrm{w}^{*}\right)=\mathrm{US} \$ 692 \mathrm{ha}^{-1}$ e a lâmina de água que produz uma receita líquida equivalente àquela obtida pela irrigação sem déficit é $\mathrm{w}_{\mathrm{el}}=467$ $\mathrm{mm}$ sendo $\mathrm{z}\left(\mathrm{w}_{\mathrm{el}}\right)=\mathrm{US} \$ 672 \mathrm{ha}^{-1}$. Os valores $\mathrm{w}_{\mathrm{m}}=573 \mathrm{~mm} \mathrm{e} \mathrm{w}_{\mathrm{el}}=467 \mathrm{~mm}$ representam o intervalo em que o déficit de irrigação é mais rentável, pois a receita líquida, dentro desse intervalo, é maior que a obtida com a irrigação plena (Figura 3).

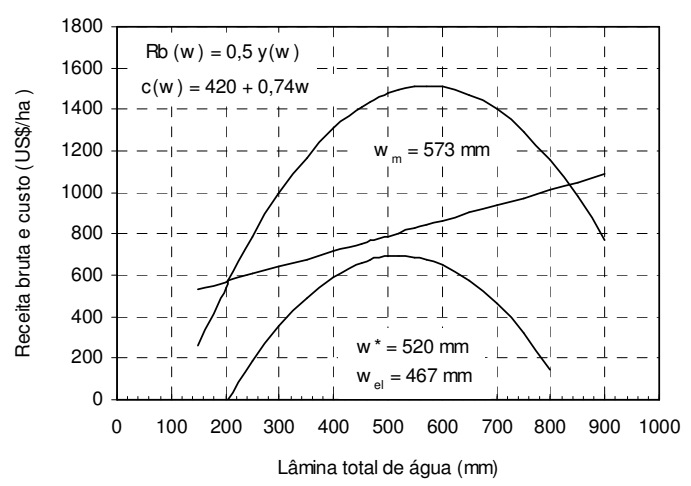

Figura 3 - Custos, receita bruta e receita líquida para a produção de feijoeiro, em função da lâmina total de água aplicada, para $c_{f}=U S \$ 420$ $h a^{-1} ; c_{w}=U S \$ 0,74 \mathrm{~mm}^{-1} \mathrm{ha}^{-1}$ e $p=U S \$ 0,5 \mathrm{~kg}^{-1}$, considerando limitação na disponibilidade de terra.

Em relação à irrigação sem déficit, o nível de irrigação de máximo lucro economiza $53 \mathrm{~mm}$ de água $(9,25 \%)$, sendo este o déficit ótimo (Tabela 1). A irrigação com a lâmina de água $\mathrm{w}_{\mathrm{el}}=467 \mathrm{~mm}$ economiza $106 \mathrm{~mm}$ de água (18,50\%), sendo este um déficit economicamente viável. Para a lâmina ótima de irrigação, em relação à lâmina para a produção máxima, a receita líquida por $\mathrm{m}^{3}$ de água aplicada aumentou de US\$0,1173 $\mathrm{m}^{-3}$ para US\$0,1331 $\mathrm{m}^{-3}$, representando um acréscimo de $13,47 \%$. No limite inferior do intervalo de déficit viável, o aumento foi de $22,63 \%$.

Observando-se os valores da Tabela 1 , pode-se verificar que: (a) mantendo-se o preço do produto (p), a lâmina ótima de irrigação diminui enquanto os custos 
associados à água de irrigação $\left(\mathrm{c}_{\mathrm{w}}\right)$ aumentam; (b) para uma mesma relação $\mathrm{c}_{\mathrm{w}} / \mathrm{p}$, a lâmina ótima mantém-se constante; (c) a receita líquida máxima aumenta à medida que $\mathrm{c}_{\mathrm{w}} / \mathrm{p}$ diminui, atingindo maiores valores para relações menores que 1 ; (d) sendo p baixo e $\mathrm{c}_{\mathrm{w}}$ alto, mesmo a aplicação da lâmina ótima pode não justificar o investimento em irrigação; (e) mantendo-se p, o acréscimo na receita líquida ótima por $\mathrm{m}^{3}$ de água aplicada, em relação à irrigação plena, aumenta com o aumento de $\mathrm{c}_{\mathrm{w}}$; (f) mantendo-se $\mathrm{p}$, o déficit econômico de irrigação aumenta com o aumento de $\mathrm{c}_{\mathrm{w}}$; $(\mathrm{g})$ a receita líquida é muito dependente de $\mathrm{p}$ e, mantendo-se $\mathrm{c}_{\mathrm{w}}$, a lâmina ótima aumenta com o aumento de p e (h) maiores déficits econômicos de irrigação estão associados aos maiores valores de $\mathrm{c}_{\mathrm{w}}$.

\section{Maximização da receita líquida com restrição de água}

Quando a quantidade de irrigação é limitada pela disponibilidade de água ou pela capacidade do sistema e a terra é relativamente abundante, a estratégia ótima de irrigação é aplicar uma lâmina de água que maximiza a receita líquida por unidade de volume de água (Frizzone, 1998). A restrição de água pode ser representada pela seguinte função:

$$
g=x w-V=0
$$

sendo V o volume de água disponível. ser formulada:

A seguinte função Lagrangeana pode

$\left.L(x, w, \lambda)=x\left[y(w) p-c_{0}-h(w)-c_{w} w\right)\right]-\lambda(x w-V)$

em que o multiplicador de Lagrange $\lambda$ representa o preço sombra da água, que é o acréscimo da receita líquida por unidade de volume de água adicional. Derivando-se L em relação a $\mathrm{x}$, w e $\mathrm{V}$ e igualando-se as derivadas parciais a zero, obtêm-se:

$$
\begin{gathered}
\frac{\partial L}{\partial x}=y(w) p-c_{0}-h(w)-c_{w} w-\lambda w=0 \\
\frac{\partial L}{\partial w}=x\left(\frac{d y}{d w} p-\frac{d h}{d w}-c_{w}\right)-\lambda x=0 \\
\frac{\partial L}{\partial \lambda}=-x w+V=0
\end{gathered}
$$

Da equação (32), obtém-se que o preço sombra da água é:

$$
\lambda=\frac{d y}{d w} p-\frac{d h}{d w}-c_{w}
$$

Quando a disponibilidade de água para irrigação é restrita, o custo de oportunidade da água constitui o fator mais importante no manejo da irrigação. Sendo este o caso, a redução na quantidade de água aplicada deverá ser a estratégia racional de manejo da irrigação e a água economizada pela irrigação com déficit deve ser usada para irrigar uma área adicional, aumentando a receita líquida da propriedade agrícola. O acréscimo potencial da receita líquida proveniente do acréscimo da área irrigada é o custo de oportunidade da água e representa o maior preço que se poderá pagar para alocar uma unidade de volume de água para aquela atividade. No ponto ótimo, o valor líquido do produto marginal da água iguala-se à soma do preço sombra e do preço da água:

$$
\begin{aligned}
& \frac{d y}{d w} p-\frac{d h}{d w}=\lambda+c_{w} \\
& \text { Comparando-se as equações (31) e } \\
& \text { (34), obtém-se: } \\
& \frac{y(w) p-h(w)-w c_{w}-c_{0}}{w}=\frac{d y}{d w} p-\frac{d h}{d w}-c_{w}
\end{aligned}
$$


Tabela 1 - Irrigação ótima para diferentes combinações de preço do produto (p) e custos que dependem diretamente da quantidade de água aplicada $\left(\mathrm{c}_{\mathrm{w}}\right)$

\begin{tabular}{|c|c|c|c|c|c|c|c|}
\hline \multirow[b]{2}{*}{$\left(\mathrm{US} \$ \mathrm{~kg}^{-1}\right)$} & \multirow[b]{2}{*}{$\left(\mathrm{US} \$ \mathrm{~mm}^{-1} \mathrm{ha}^{-1}\right)$} & \multicolumn{2}{|c|}{ Uso de água } & \multicolumn{4}{|c|}{ Receita Líquida } \\
\hline & & $\begin{array}{l}\text { aplicada } \\
(\mathrm{mm})\end{array}$ & $\begin{array}{c}\text { déficit } \\
(\%)\end{array}$ & $\begin{array}{c}\mathrm{Z}(\mathrm{w}) \\
\mathrm{USS} \mathrm{ha}^{-1}\end{array}$ & $\begin{array}{c}\text { acréscimo } \\
(\%)\end{array}$ & $\begin{array}{c}\mathrm{Z}(\mathrm{w}) \\
\mathrm{US} \$ \mathrm{~m}^{-3}\end{array}$ & $\begin{array}{c}\text { acréscimo } \\
(\%)\end{array}$ \\
\hline \multirow{9}{*}{0,30} & & $\mathrm{w}_{\mathrm{m}}=573$ & & 306 & & 0,0534 & \\
\hline & 0,32 & $\mathrm{w}^{*}=535$ & 7,10 & 312 & 1,96 & 0,0583 & 9,18 \\
\hline & $\left(\mathrm{c}_{\mathrm{w}} / \mathrm{p}=1,07\right)$ & $\mathrm{w}_{\mathrm{el}}=496$ & 15,52 & 306 & & 0,0617 & 15,54 \\
\hline & & $\mathrm{w}_{\mathrm{m}}=573$ & & 203 & & 0,0354 & \\
\hline & 0,50 & $\mathrm{w}^{*}=513$ & 11,70 & 218 & 7,39 & 0,0425 & 20,06 \\
\hline & $\left(\mathrm{c}_{\mathrm{w}} / \mathrm{p}=1,67\right)$ & $\mathrm{w}_{\mathrm{el}}=454$ & 26,21 & 203 & & 0,0447 & 26,27 \\
\hline & & $\mathrm{w}_{\mathrm{m}}=573$ & & 66 & & 0,0115 & \\
\hline & 0,74 & $\mathrm{w}^{*}=485$ & 18,14 & 98 & 48,49 & 0,0202 & 75,65 \\
\hline & $\left(\mathrm{c}_{\mathrm{w}} / \mathrm{p}=2,47\right)$ & $\mathrm{w}_{\mathrm{el}}=396$ & 44,70 & 66 & & 0,0167 & 45,22 \\
\hline \multirow{9}{*}{0,50} & & $\mathrm{w}_{\mathrm{m}}=573$ & & 913 & & 0,1593 & \\
\hline & 0,32 & $\mathrm{w}^{*}=550$ & 4,18 & 916 & 0,33 & 0,1665 & 4,52 \\
\hline & $\left(c_{w} / p=0,64\right)$ & $\mathrm{w}_{\mathrm{el}}=527$ & 8,73 & 913 & & 0,1732 & 8,73 \\
\hline & & $\mathrm{w}_{\mathrm{m}}=573$ & & 809 & & 0,1412 & \\
\hline & 0,50 & $\mathrm{w}^{*}=534$ & 7,30 & 819 & 1,24 & 0,1534 & 8,64 \\
\hline & $\left(\mathrm{c}_{\mathrm{w}} / \mathrm{p}=1,00\right)$ & $\mathrm{w}_{\mathrm{el}}=501$ & 14,37 & 809 & & 0,1615 & 14,38 \\
\hline & & $\mathrm{w}_{\mathrm{m}}=573$ & & 672 & & 0,1173 & \\
\hline & 0,74 & $\mathrm{w}^{*}=520$ & 9,25 & 692 & 2,98 & 0,1331 & 13,47 \\
\hline & $\left(\mathrm{c}_{\mathrm{w}} / \mathrm{p}=1,48\right)$ & $\mathrm{w}_{\mathrm{el}}=467$ & 18,50 & 672 & & 0,1439 & 22,68 \\
\hline \multirow{9}{*}{0,70} & & $\mathrm{w}_{\mathrm{m}}=573$ & & 1519 & & 0,2651 & \\
\hline & 0,32 & $\mathrm{w}^{*}=556$ & 3,06 & 1522 & 0,20 & 0,2737 & 3,24 \\
\hline & $\left(\mathrm{c}_{\mathrm{w}} / \mathrm{p}=0,46\right)$ & $\mathrm{w}_{\mathrm{el}}=539$ & 6,31 & 1519 & & 0,2818 & 6,30 \\
\hline & & $\mathrm{w}_{\mathrm{m}}=573$ & & 1416 & & 0,2471 & \\
\hline & 0,50 & $\mathrm{w}^{*}=547$ & 4,75 & 1422 & 0,42 & 0,2600 & 5,22 \\
\hline & $\left(\mathrm{c}_{\mathrm{w}} / \mathrm{p}=0,71\right)$ & $\mathrm{w}_{\mathrm{el}}=522$ & 9,77 & 1416 & & 0,2713 & 9,79 \\
\hline & & $\mathrm{w}_{\mathrm{m}}=573$ & & 1278 & & 0,2230 & \\
\hline & 0,74 & $\mathrm{w}^{*}=535$ & 7,10 & 1293 & 1,17 & 0,2417 & 8,39 \\
\hline & $\left(\mathrm{c}_{\mathrm{w}} / \mathrm{p}=1,06\right)$ & $\mathrm{w}_{\mathrm{el}}=497$ & 15,29 & 1278 & & 0,2571 & 15,29 \\
\hline
\end{tabular}

R. Bras. Agric. Irrigada, v.1, n.1, p.24-49, 2007. 
isto é, sendo a água restrita, a alocação ótima desse recurso requer que a receita líquida por unidade de volume de água seja igual à receita líquida marginal. Pode-se observar que, sob tais condições, a receita líquida por unidade de volume de água é máxima. Esse resultado pode ser resumido na seguinte asserção: quando a disponibilidade de água é o único fator limitante da produção, a alocação de água deve objetivar a maximização da receita líquida por unidade de volume de água.

Assumindo a condição simplificativa estabelecida pela equação (10) e aplicando-se operadores de Lagrange das relações $\partial \mathrm{L} / \partial \mathrm{x} \mathrm{e}$ $\partial \mathrm{L} / \partial \mathrm{w}$ obtém-se:

$p\left(r_{0}+r_{1} w+r_{2} w^{2}\right)-c_{f}-w c_{w}=w\left[p\left(r_{1}+2 r_{2} w\right)-c_{w}\right]$

de onde resulta a quantidade ótima de irrigação:

$$
w^{*}=\sqrt{\frac{p r_{0}-c_{f}}{p r_{2}}}
$$

Neste caso, também existe uma quantidade de água $\mathrm{w}_{\mathrm{ew}}$ que produz uma receita líquida equivalente àquela obtida com um nível de irrigação $\mathrm{w}_{\mathrm{m}}$ (Figura 4). Dessa forma, para $\mathrm{Z}\left(\mathrm{w}_{\mathrm{m}}\right)$ e $\mathrm{Z}\left(\mathrm{w}_{\mathrm{ew}}\right)$, tem-se:

$$
\begin{aligned}
& Z\left(w_{m}\right)=x z\left(w_{m}\right) \\
& Z\left(w_{e w}\right)=x z\left(w_{e w}\right) \\
& Z\left(w_{m}\right)=\frac{V}{w_{m}} z\left(w_{m}\right) \\
& Z\left(w_{e w}\right)=\frac{V}{w_{e w}} z\left(w_{e w}\right)
\end{aligned}
$$

Igualando-se as equações (41) e (42), obtém-se:

$$
\frac{V}{w_{e w}}\left[p y\left(w_{e w}\right)-c_{f}-c_{w} w_{e w}\right]=\frac{V}{w_{m}}\left[p y\left(w_{m}\right)-c_{f}-c_{w} w_{m}\right]
$$

Substituindo-se a função de produção aplicada para $\mathrm{w}_{\mathrm{ew}}$ e $\mathrm{w}_{\mathrm{m}}$ e a equação (4) na equação (43), e resolvendo-se para $\mathrm{w}_{\mathrm{ew}}$, obtém-se :

$$
w_{\text {ew }}=\frac{-b+\sqrt{b^{2}-4 a c}}{2 a}
$$

em que:

$$
\begin{aligned}
& a=p r_{2} \\
& b=\frac{4 p r_{0} r_{2}+p r_{1}^{2}-4 r_{2} c_{f}}{2 r_{1}} \\
& c=p r_{0}-c_{f}
\end{aligned}
$$

Aplicação 2: O objetivo é determinar a quantidade ótima de irrigação para a cultura da melancia, irrigada por gotejamento, considerando-se a água como fator limitante da produção. A função de produção águacultura (Figura 5) foi obtida no campo experimental da Embrapa - Centro de Pesquisa Agropecuária do Meio-Norte, em Parnaíba, PI, cujas condições edafoclimáticas são representativas da região dos Tabuleiros Costeiros do Piauí (Andrade Júnior et al.,2001). Observa-se que, para a estratégia de irrigação sem déficit, a produtividade máxima é atingida para $356 \mathrm{~mm}$ de água, dentro da faixa ideal considerada para a cultura (300 $\mathrm{mm}$ a $400 \mathrm{~mm}$ ), segundo Doorenbos e Kassan (1979).

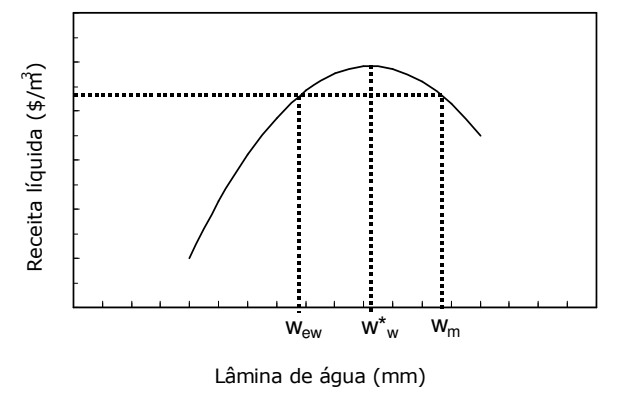

Figura 4- Intervalo para o manejo racional da irrigação com déficit, quando a disponibilidade de água é fator limitante da produção 
$\mathrm{Na}$ Figura 6, são apresentadas as curvas de receita bruta, custos de produção e receita líquida por hectare, para a cultura da melancia, para o preço do produto de US $\$ 0,10 \mathrm{~kg}^{-1}$. Para compor o custo total de produção, considerou-se um custo médio de produção de US $\$ 1.244 \mathrm{ha}^{-1}$, excetuando-se o custo diretamente associado à água de irrigação. Já para os custos diretamente dependentes da quantidade de água aplicada, considerou-se US $\$ 0,30 \mathrm{~mm}^{-1} \mathrm{ha}^{-1}$. Nessas condições, a máxima receita líquida por hectare foi US\$3.035,3, para uma lâmina de água de $350 \mathrm{~mm}$. Mas, na condição de água restrita, a lâmina ótima de irrigação depende do preço do produto e a estratégia de irrigação é maximizar a receita líquida por unidade de volume de água aplicada, o que não corresponde à maximização da receita líquida por unidade de área.

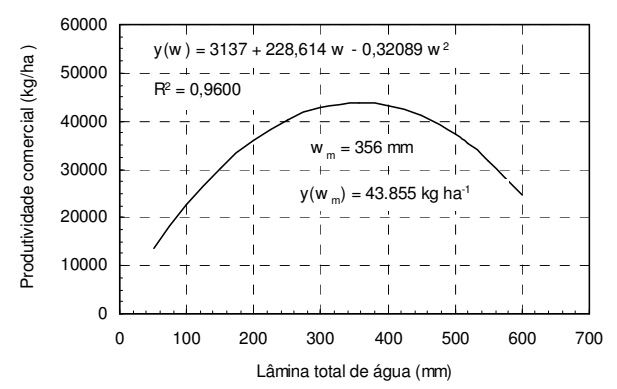

Figura 5 - $\quad$ Função de produção a para a melancia, obtida para as condições edafoclimáticas da região dos Tabuleiros Costeiros do Piauí (Andrade Júnior et al., 2001).

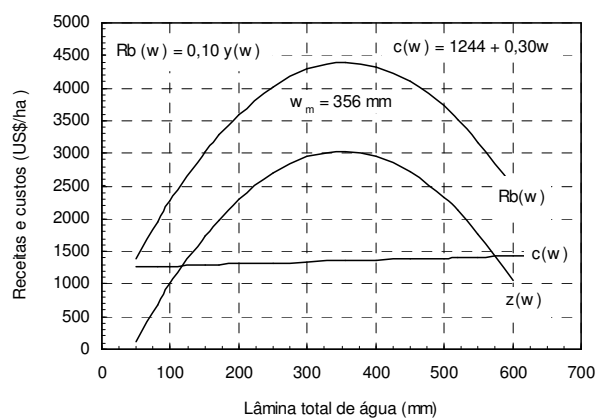

Figura 6 - Funções de receita bruta, de custos e de receita líquida para a melancia, em relação à quantidade de água aplicada, para $p=U S \$ 0,10$ $\mathrm{kg}^{-1}, c_{f}=U S \$ 1.244 \mathrm{ha}^{-1}$ e $c_{w}=U S \$ 0,30 \mathrm{~mm}^{-1} \mathrm{ha}^{-}$
Na Figura 7, verifica-se que a lâmina ótima é $170 \mathrm{~mm}$, o que corresponde a um déficit econômico de água de $186 \mathrm{~mm}$ em relação à lâmina para irrigação sem déficit. Nesse caso, a economia de água é de 52\%, podendo ser utilizada para a irrigação de área adicional. A lâmina de água que proporciona uma receita líquida equivalente à irrigação sem déficit é $81 \mathrm{~mm}$, correspondendo a uma economia de água de $77 \%$. O intervalo de manejo da água entre $81 \mathrm{~mm}$ e $356 \mathrm{~mm}$ define uma região economicamente viável para a irrigação com déficit, sendo $170 \mathrm{~mm}$ a quantidade ótima de irrigação.

Assumindo, por exemplo, que o volume de água disponível, durante o ciclo da cultura, é $20.000 \mathrm{~m}^{3}$, a irrigação sem déficit $(356 \mathrm{~mm})$ permitiria o cultivo de 5,6 ha de melancia e proporcionaria uma receita líquida de US\$3.034,70 ha ${ }^{-1}$, ou US\$16.994,30 para a área total. Já a utilização da lâmina ótima $(170 \mathrm{~mm})$ possibilitaria aumentar a área irrigada para 11,8 ha, com uma receita líquida de US\$1.977,8 ha ${ }^{-1}$, ou US $\$ 23.338,0$ para a área total. Também a água economizada poderia ser utilizada para a irrigação de outra cultura.

$\mathrm{Na}$ Tabela 2, são apresentadas as estratégias de irrigação e as respectivas receitas líquidas por unidade de volume de água aplicada, considerando-se quatro preços da melancia (US\$0,05 $\mathrm{kg}^{-1}$, US\$0,10 $\mathrm{kg}^{-1}$, US\$ $0,15 \mathrm{~kg}^{-1}$ e US\$ $\left.0,30 \mathrm{~kg}^{-1}\right)$. Os três últimos valores foram selecionados em função dos preços médios mensais, no período de janeiro de 1994 a dezembro de 1998, no mercado atacadista de Teresina e variaram de US\$0,10 $\mathrm{kg}^{-1}$ a US\$0,30 $\mathrm{kg}^{-1}$ (ANDRADE JÚNIOR et al, 2001). Para analisar as estratégias de irrigação com um baixo preço do produto utilizou-se o valor US\$0,05 kg-1. As receitas líquidas foram calculadas para $c_{w}=$ US $\$ 0,30 \mathrm{~mm}^{-1} \mathrm{ha}^{-1}$. Observa-se que a lâmina ótima de irrigação e a lâmina equivalente diminuem enquanto aumenta o preço do produto (Tabela 2), isto é, o déficit econômico de irrigação é maior para maiores preços do produto. Para um preço do produto de US $\$ 0,10 \mathrm{~kg}^{-1}$, a lâmina ótima de irrigação durante o ciclo deverá ser

R. Bras. Agric. Irrigada, v.1, n.1, p.24-49, 2007. 
$170 \mathrm{~mm}$, o que corresponde a 52\% de déficit. Já a lâmina equivalente é $81 \mathrm{~mm}$, isto é, $77 \%$ de déficit.

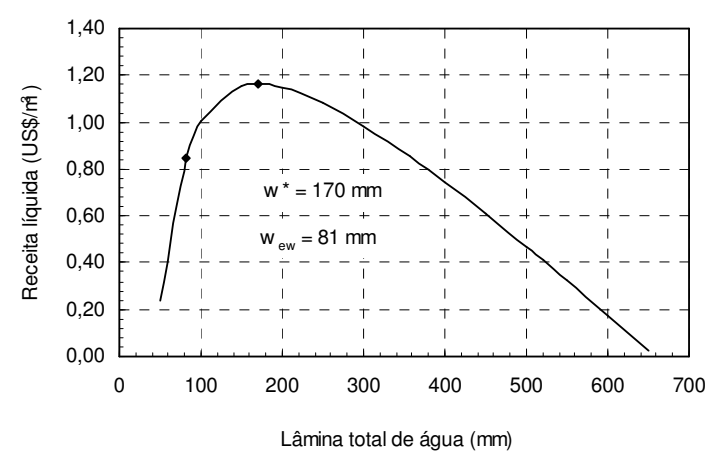

Figura 7 - Receita líquida por $m^{3}$ de água aplicada, para a cultura da melancia, em relação à lâmina total de água aplicada, para $p=U S \$$ $0,10 \mathrm{~kg}^{-1}, c_{f}=$ US\$ $1.244 \mathrm{ha}^{-1}$ e $c_{w}=U S \$ 0,30$ $\mathrm{mm}^{-1} \mathrm{ha}^{-1}$.

É importante também considerar o volume total de produção. Com a redução no uso da água, uma quantidade adicional de terra poderá ser cultivada, com um conseqüente aumento na produção total. Na Tabela 2, observa-se que, para $\mathrm{p}=\mathrm{US} \$ 0,10$ $\mathrm{kg}^{-1}$, se podem dobrar a área cultivada e a produção com o uso da lâmina ótima, relativamente à irrigação sem déficit. Nesse caso, embora a receita líquida por hectare se reduza em aproximadamente $34,8 \%$ (US\$3034,7 ha ${ }^{-1}$ para US\$1977,8 $\mathrm{ha}^{-1}$ ), a receita líquida total aumenta $36,2 \%$, em decorrência do aumento da área cultivada.

É importante salientar que, especificamente no caso da melancia, a adoção de elevados déficits de água pode reduzir o peso médio dos frutos, tornando-os não aceitáveis no mercado consumidor. O ideal é conciliar a quantidade a ser produzida e a qualidade dessa produção com a irrigação com déficit, tendo em vista as preferências do mercado consumidor. Dessa forma, mesmo para preços elevados do produto, dificilmente se poderia adotar um déficit elevado. Por exemplo, admitindo-se que, para produzir frutos de boa qualidade sejam necessários pelo menos $200 \mathrm{~mm}$ de água durante o ciclo, e que o preço do produto no mercado esteja em US\$ $0,15 \mathrm{~kg}^{-1}$, a lâmina ótima de irrigação de $127 \mathrm{~mm}$ não deveria ser utilizada. Nesse caso, utilizar-se-ia a lâmina de 200 mm, porque corresponde ao intervalo de irrigação economicamente viável.

Tabela 2 - Estratégias de irrigação da cultura da melancia na região dos Tabuleiros Costeiros do Piauí, considerando-se $\mathrm{c}_{\mathrm{w}}=\mathrm{US} \$ 0,30 \mathrm{~mm}^{-1} \mathrm{ha}^{-1}$ e quatro preços do produto.

\begin{tabular}{|c|c|c|c|c|c|c|}
\hline $\begin{array}{c}\mathrm{p} \\
\left(\mathrm{US} \$ \mathrm{~kg}^{-1}\right)\end{array}$ & $\begin{array}{l}\text { Uso de água } \\
\qquad(\mathrm{mm})\end{array}$ & $\begin{array}{l}\text { Déficit } \\
(\%)\end{array}$ & $\begin{array}{c}\mathrm{y}(\mathrm{w}) \\
\left(\mathrm{kg} \mathrm{ha}^{-1}\right)\end{array}$ & $\begin{array}{c}\mathrm{z}(\mathrm{w}) \\
\left(\mathrm{US} \$ \mathrm{~m}^{-3}\right)\end{array}$ & $\begin{array}{c}\text { Área irrigada } \\
\text { (ha) }\end{array}$ & $\begin{array}{c}\text { Produção } \\
(\mathrm{kg})\end{array}$ \\
\hline \multirow{3}{*}{0,05} & $\mathrm{w}_{\mathrm{m}}=356$ & & $43.855,3$ & 0,24 & 1,00 & $43.855,3$ \\
\hline & $\mathrm{w}^{*}=260$ & 27 & $40.884,5$ & 0,27 & 1,37 & $56.011,8$ \\
\hline & $\mathrm{w}_{\mathrm{ew}}=190$ & 47 & $34.989,5$ & 0,24 & 1,87 & \\
\hline \multirow{3}{*}{0,10} & $\mathrm{w}_{\mathrm{m}}=356$ & & $43.855,3$ & 0,85 & 1,00 & $43.855,3$ \\
\hline & $\mathrm{w}^{*}=170$ & 52 & $32.727,7$ & 1,16 & 2,09 & $68.400,9$ \\
\hline & $\mathrm{w}_{\mathrm{ew}}=81$ & 77 & $19.549,4$ & 0,85 & 4,40 & \\
\hline \multirow{3}{*}{0,15} & $\mathrm{w}_{\mathrm{m}}=356$ & & $43.855,3$ & 1,47 & 1,00 & $43.855,3$ \\
\hline & $\mathrm{w}^{*}=127$ & 64 & $26.995,3$ & 2,18 & 2,80 & $75.474,8$ \\
\hline & $\mathrm{w}_{\mathrm{ew}}=45$ & 87 & $12.774,8$ & 1,47 & 7,91 & \\
\hline \multirow{3}{*}{0,30} & $\mathrm{w}_{\mathrm{m}}=356$ & & $43.855,3$ & 3,32 & 1,00 & $43.855,3$ \\
\hline & $\mathrm{w}^{*}=56$ & 84 & $14.933,1$ & 5,74 & 6,36 & $94.974,5$ \\
\hline & $\mathrm{w}_{\mathrm{ew}}=9$ & 98 & $5.168,5$ & 3,32 & 39,55 & \\
\hline
\end{tabular}

R. Bras. Agric. Irrigada, v.1, n.1, p.3-11, 2007. 


\section{OTIMIZAÇÃO DA IRRIGAÇÃO PARA MÚLTIPLAS ÁREAS E CULTURAS}

O problema de otimização é mais complexo quando múltiplas áreas e culturas devem ser irrigadas com suprimento limitado de água. A escassez de água implica uma análise de custo de oportunidade e o tomador de decisão deve considerar todas as áreas e culturas e todo o uso alternativo da água simultaneamente, alocando uma quantidade maior de água para culturas mais rentáveis, ou até disponibilizando água para usos externos à propriedade. Análises desses casos levam à utilização de técnicas de programação matemática para a otimização das atividades, possibilitando quantificar, de forma otimizada, o uso dos recursos para satisfazer determinado objetivo, seja a maximização da receita líquida ou a minimização dos custos, sob restrições na disponibilidade dos recursos (Dudley; Howell; Musgravi, 1971; Kumar; Khepar, 1980; Frizzone; Botrel; Arce, 1994; Dantas Neto; Azevedo; Frizzone, 1997; Rodrigues et al., 2000; Gorantiwar; Smout, 2003).

Frizzone et al. (1997) desenvolveram um modelo de programação linear separável, para estudar a alocação de água de irrigação no Projeto Senador Nilo Coelho, localizado em Petrolina - PE, com o objetivo de maximizar a receita líquida. Assumiu-se que as funções de produção água-cultura disponíveis representavam adequadamente as relações água-produção. Tais funções, não lineares, foram incorporadas ao modelo de programação linear, que considera um conjunto de fatores técnicos que influenciam a rentabilidade do projeto de irrigação. As funções não lineares foram aproximadas por funções lineares por partes, possibilitando a utilização do método Simplex para a solução. Explicitaram-se restrições na disponibilidade de água, de área e de mercado. Como resultados, foram obtidos os níveis ótimos de irrigação, o plano ótimo de exploração e o custo de oportunidade dos recursos escassos.
A receita bruta do projeto foi formulada do seguinte modo:

$$
\mathrm{lb}=\sum_{\mathrm{i}=1}^{\mathrm{n}} \mathrm{p}_{\mathrm{i}} \mathrm{x}_{\mathrm{i}} \mathrm{y}_{\mathrm{i}}(\mathrm{w})
$$

em que: Ib - receita bruta obtida com $n$ culturas numa área $x$, em US\$; $p_{i}$ - preço de venda do produto da cultura i, em US\$.ha ${ }^{-1}$; $\mathrm{y}_{\mathrm{i}}(\mathrm{w})$ - produtividade da cultura $\mathrm{i}$ em função da lâmina de irrigação, em kg.ha ${ }^{-1} ; x_{i}$ - área plantada e irrigada com a cultura i, em há, e $n$ - um inteiro que define o número de culturas.

Sendo a água o único fator variável, para a cultura i o custo de produção será:

$$
c_{i}=c_{f i}+c_{w} w_{i}
$$

ou, para o projeto:

$$
C=\sum_{i=1}^{n} c_{f i} x_{i}+\sum_{i=1}^{n} c_{w} w_{i} x_{i}
$$

sendo, $\mathrm{C}$ os custos de produção da unidade econômica.

A função-objetivo para o projeto é formulada como:

$$
\text { Maximizar } Z=\sum_{i=1}^{n} p_{i} y_{i}(w) x_{i}-\sum_{i=1}^{n} c_{f i} x_{i}-\sum_{i=1}^{n} c_{w} x_{i} w_{i}
$$

sendo $\mathrm{Z}$ a receita líquida do projeto decorrente do cultivo de $\mathrm{n}$ culturas com lâmina de irrigação $\mathrm{w}_{\mathrm{i}}$.

As restrições a que está sujeita a função-objetivo são expressas da seguinte forma:

$$
\begin{aligned}
& \sum_{i=1}^{n} w_{i} x_{i} \leq V a \\
& \sum_{i=1}^{n} a_{i j} x_{i} \leq A_{j}, \text { para } j=1,2, \ldots, J \\
& x_{i} \geq 0
\end{aligned}
$$

em que: Va - volume anual de água disponível, em mm.ha; $a_{i j}$ - quantidade do

R. Bras. Agric. Irrigada, v.1, n.1, p.24-49, 2007. 
insumo $\mathrm{j}$, por unidade de área, necessária à iésima cultura e $\mathrm{A}_{\mathrm{j}}$ - disponibilidade máxima do insumo $\mathrm{j}$.

O modelo formulado constitui um problema de programação não-linear, uma vez que a função-objetivo contém uma função não linear $\left[\mathrm{y}_{\mathrm{i}}(\mathrm{w})\right]$. Entretanto, esta função pode ser linearizada através da técnica de linearização por partes e o modelo, tratado como um problema de programação linear separável (McMillan Jr., 1970).

A seguir, desenvolve-se o modelo de programação linear separável, aproximandose as funções de produção água-cultura, nãolineares, por funções lineares por partes, possibilitando a utilização do método simplex para a solução. Na Figura 8, apresenta-se uma função de produção água-cultura genérica, linearizada por partes. Tal função foi dividida em $\mathrm{k}$ segmentos lineares, sendo $\mathrm{k}$ um número inteiro $(\mathrm{k}=1,2, \ldots, \mathrm{s})$.

Observa-se, na Figura 8, que uma redução na lâmina de irrigação da cultura i de $\mathrm{w}_{\mathrm{i} 0}$ para $\mathrm{w}_{\mathrm{i} 1}\left(\Delta \mathrm{w}_{\mathrm{i} 1}\right)$ implica uma redução da produtividade de $\mathrm{y}_{\mathrm{i} 0}$ para $\mathrm{y}_{\mathrm{i} 1}\left(\Delta \mathrm{y}_{\mathrm{i} 1}\right)$; uma redução de $\mathrm{w}_{\mathrm{i} 1}$ para $\mathrm{w}_{\mathrm{i} 2}\left(\Delta \mathrm{w}_{\mathrm{i} 2}\right)$ resulta em $\mathrm{y}_{\mathrm{i} 1}$ para $\mathrm{y}_{\mathrm{i} 2}\left(\Delta \mathrm{y}_{\mathrm{i} 2}\right)$ e assim sucessivamente. Generalizando, uma redução na lâmina de irrigação de $\mathrm{w}_{\mathrm{i} \text { k-1 }}$ para $\mathrm{w}_{\mathrm{ik}}\left(\Delta \mathrm{w}_{\mathrm{ik}}\right)$ resulta uma redução na produtividade de $y_{\mathrm{i} k-1}$ para $\mathrm{y}_{\mathrm{ik}}$ $\left(\Delta \mathrm{y}_{\mathrm{ik}}\right)$.

Na função de resposta (Figura 8), são identificados dois pontos de referência:

(a) $\mathrm{y}_{\mathrm{i} 0}, \mathrm{w}_{\mathrm{i} 0}$ - representa a produtividade máxima e a correspondente lâmina de irrigação;

(b) $\mathrm{y}_{\text {is }}, \mathrm{w}_{\text {is }}-$ representa a produtividade mínima e a correspondente lâmina de irrigação. A região entre $\mathrm{y}_{\mathrm{i} 0}$ e $\mathrm{y}_{\mathrm{is}}$ é a região econômica de produção. Ela inicia onde o produto físico médio é máximo e termina onde o produto físico marginal é zero. A lâmina de irrigação deve ser selecionada em algum ponto entre s e zero, onde a produtividade marginal da água se iguala a seu preço.

O modelo representado pelas equações (51) a (54) pode ser modificado de forma a considerar as funções de respostas lineares por partes, para $\mathrm{n}$ culturas.

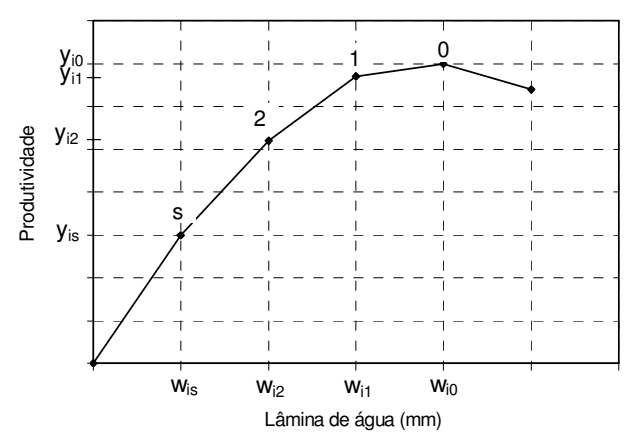

Figura 8 - Representação esquemática de uma função de resposta linearizada por partes.

Ao se considerar que as culturas são irrigadas com lâmina para a máxima produtividade $\left(\mathrm{w}_{\mathrm{i} 0}\right)$, para uma área $\mathrm{x}$, obtémse a seguinte função de receita bruta:

$$
\mathrm{Ib}_{0}=\sum_{\mathrm{i}=1}^{\mathrm{n}} \mathrm{x}_{\mathrm{i} 0} \mathrm{y}_{\mathrm{i} 0} \mathrm{p}_{\mathrm{i}}
$$

em que, $\mathrm{Ib}_{0}$ é a receita bruta obtida com $\mathrm{n}$ culturas irrigadas com lâmina $\mathrm{w}_{0}$, em \$.

A redução da lâmina de irrigação de $\mathrm{w}_{\mathrm{i} 0}$ para $\mathrm{w}_{\mathrm{i} 1}\left(\Delta \mathrm{w}_{\mathrm{i} 1}\right)$ proporciona uma redução da receita bruta da cultura $i$ de $I b_{i 0}$ para $I b_{i 1}$ $\left(\Delta \mathrm{Ib}_{\mathrm{il}}\right)$. Da mesma forma, uma redução da lâmina de $\mathrm{w}_{\mathrm{i} 1}$ para $\mathrm{w}_{\mathrm{i} 2}\left(\Delta \mathrm{w}_{\mathrm{i} 2}\right)$ resulta uma redução da receita bruta de $I_{\text {i1 }}$ para $I_{\text {i2 }}$ $\left(\Delta \mathrm{Ib}_{\mathrm{i} 2}\right)$, e assim sucessivamente. Para uma cultura i, tem-se que a redução total da receita bruta, até um ponto $\mathrm{k}$, será:

$$
\Delta \mathrm{l}_{\mathrm{k}}=\sum_{\mathrm{i}=1}^{\mathrm{n}} \Delta \mathrm{lb}_{\mathrm{ik}}
$$

Considerando-se $\mathrm{n}$ culturas e cada uma proporcionando $\Delta \mathrm{Ib}_{\mathrm{ik}}$, pode-se escrever:

$$
\Delta \mathrm{lb}=\sum_{\mathrm{i}=1}^{\mathrm{n}} \sum_{\mathrm{k}=1}^{\mathrm{s}} \Delta \mathrm{lb}_{\mathrm{ik}}
$$

Assumindo-se que não há variação da área total disponível para cultivo irrigado quando se varia a lâmina de irrigação, e que apenas a produtividade da cultura pode variar, para $\mathrm{n}$ culturas, tem-se: 


$$
\Delta \mathrm{lb}=\sum_{\mathrm{i}=1}^{\mathrm{n}} \sum_{\mathrm{k}=1}^{\mathrm{s}} \mathrm{x}_{\mathrm{ik}} \Delta \mathrm{y}_{\mathrm{ik}} \mathrm{p}_{\mathrm{i}}
$$

A receita bruta da unidade econômica, decorrente de $\mathrm{n}$ culturas, utilizando-se uma lâmina de irrigação $\mathrm{W}_{\mathrm{ik}}$ inferior a $\mathrm{w}_{\mathrm{i} 0}$, pode ser expressa por:

$$
\mathrm{Ib}_{\mathrm{k}}=\sum_{\mathrm{i}=1}^{\mathrm{n}} \mathrm{x}_{\mathrm{i0}} \mathrm{y}_{\mathrm{i} 0} \mathrm{p}_{\mathrm{i}}-\sum_{\mathrm{i}=1}^{\mathrm{n}} \sum_{\mathrm{k}=1}^{\mathrm{s}} \mathrm{x}_{\mathrm{ik}} \Delta \mathrm{y}_{\mathrm{ik}} \mathrm{p}_{\mathrm{i}}
$$

O custo de produção da cultura i, para uma lâmina de irrigação $\mathrm{w}_{\mathrm{i} 0} \mathrm{e}$ área $\mathrm{x}_{\mathrm{i} 0}$, será:

$$
\mathrm{c}_{\mathrm{i} 0}=\mathrm{c}_{\mathrm{fi}} \mathrm{x}_{\mathrm{i} 0}+\mathrm{c}_{\mathrm{w}} \mathrm{x}_{\mathrm{i} 0} \mathrm{w}_{\mathrm{i} 0}
$$

se:

Por conseguinte, para n culturas, tem-

$$
\mathrm{C}_{0}=\sum_{\mathrm{i}=1}^{\mathrm{n}} \mathrm{c}_{\mathrm{fi}} \mathrm{x}_{\mathrm{i} 0}+\sum_{\mathrm{i}=0}^{\mathrm{n}} \mathrm{c}_{\mathrm{w}} \mathrm{w}_{\mathrm{i} 0} \mathrm{x}_{\mathrm{i} 0}
$$

A redução na lâmina de irrigação de $\mathrm{w}_{\mathrm{i} 0}$ para $\mathrm{w}_{\mathrm{i} 1}\left(\Delta \mathrm{w}_{\mathrm{i} 1}\right)$ resulta na redução dos custos de $c_{i 0}$ para $c_{i 1}\left(\Delta c_{i 1}\right)$, e assim por diante, decorrendo a redução nos custos apenas do custo da água. Assim, por unidade de área, têm-se:

$$
\begin{aligned}
& \Delta \mathrm{c}_{\mathrm{i} 1}=\mathrm{c}_{\mathrm{w}}\left(\mathrm{w}_{\mathrm{i} 0}-\mathrm{w}_{\mathrm{i} 1}\right)=\mathrm{c}_{\mathrm{w}} \Delta \mathrm{w}_{\mathrm{i} 1} \\
& \Delta \mathrm{c}_{\mathrm{i} 2}=\mathrm{c}_{\mathrm{w}}\left(\mathrm{w}_{\mathrm{i} 1}-\mathrm{w}_{\mathrm{i} 2}\right)=\mathrm{c}_{\mathrm{w}} \Delta \mathrm{w}_{\mathrm{i} 2} \\
& \Delta \mathrm{c}_{\mathrm{ik}}=\mathrm{c}_{\mathrm{w}}\left(\mathrm{w}_{\mathrm{ik}-1}-\mathrm{w}_{\mathrm{ik}}\right)=\mathrm{c}_{\mathrm{w}} \Delta \mathrm{w}_{\mathrm{ik}}
\end{aligned}
$$

Para $\mathrm{n}$ culturas e $\mathrm{k}$ segmentos na função de produção, o custo de produção, ao se utilizar a lâmina de irrigação $w_{k}$, pode ser formulado como:

$$
\mathrm{C}=\sum_{\mathrm{i}=1}^{\mathrm{n}} \mathrm{c}_{\mathrm{fi}} \mathrm{x}_{\mathrm{i} 0}+\sum_{\mathrm{i}=1}^{\mathrm{n}} \mathrm{c}_{\mathrm{w}} \mathrm{x}_{\mathrm{i} 0} \mathrm{w}_{\mathrm{i} 0}-\sum_{\mathrm{i}=1}^{\mathrm{n}} \sum_{\mathrm{k}=1}^{\mathrm{s}} \mathrm{c}_{\mathrm{w}} \Delta \mathrm{w}_{\mathrm{ik}} \mathrm{x}_{\mathrm{ik}}
$$

A receita líquida obtida com $\mathrm{n}$ culturas na área x e lâmina de água $\mathrm{w}_{\mathrm{k}}$, será:

$$
\begin{aligned}
& Z=\left(\sum_{i=1}^{n} x_{i 0} y_{i 0}-\sum_{i=1}^{n} \sum_{k=1}^{s} x_{i k} \Delta y_{i k}\right) p_{i} \\
& -\left(\sum_{i=1}^{n} c_{f i} x_{i 0}+\sum_{i=1}^{n} c_{w} x_{i 0} w_{i 0}-\sum_{i=1}^{n} \sum_{k=1}^{s} c_{w} \Delta w_{i k} x_{i k}\right)
\end{aligned}
$$

O objetivo da unidade econômica é maximizar a função de receita líquida (equação 66), sob as seguintes restrições gerais:

(a) o volume de água consumido nas irrigações no nível $\mathrm{k}$ não deve exceder $\mathrm{o}$ volume máximo disponível:

$$
\begin{aligned}
& \sum_{i=1}^{n} x_{i 0} w_{i 0}-\sum_{i=1}^{n} \sum_{k=1}^{s} x_{i k} \Delta w_{i k} \leq V a \\
& \sum_{i=1}^{n} x_{i 0} w_{i 0}^{*}-\sum_{i=1}^{n} \sum_{k=1}^{s} x_{i k} \Delta w_{i k}^{*} \leq V m
\end{aligned}
$$

em que: $w_{i k}$ - lâmina de água aplicada durante o ciclo da cultura $i$, com nível de irrigação k,em mm; $w_{i k}^{*}$ - lâmina mensal de água aplicada à cultura $\mathrm{i}$, com nível de irrigação k, em mm; $w_{i 0}^{*}$ - lâmina mensal de água aplicada a cultura i, para máxima produtividade, em mm; $\mathrm{Va}$ - volume anual de água disponível, em mm.ha e Vm - volume mensal de água disponível, em mm.ha.

(b) restrição de área cultivada para a cultura i $\left(\mathrm{G}_{\mathrm{i}}\right)$ :

$$
\mathrm{x}_{\mathrm{i} 0} \leq \mathrm{ou} \geq \mathrm{G}_{\mathrm{i}}
$$

(c) restrição de área total cultivada em cada mês:

$$
\sum_{i=1}^{n} x_{i 0} \leq X m, \text { para } m=1,2, \ldots, 12
$$

sendo Xm a área total disponível (ha) para cultivo no mês m.

(d) não há acréscimo de área irrigada com o uso da lâmina $\mathrm{w}_{\mathrm{ik}}$ :

$$
\mathrm{x}_{\mathrm{ik}}-\mathrm{x}_{\mathrm{i} 0} \leq 0, \text { para } \mathrm{i}=1,2, \ldots, \mathrm{n}
$$

(e) não-negatividade:

$$
x_{i 0} \geq 0 \quad \text { e } \quad x_{i k} \geq 0
$$


Frizzone et al (1997) aplicaram esse modelo ao Projeto de irrigação Senador Nilo Coelho, Petrolina (PE), e a solução encontrada representou o padrão ótimo de cultivo. Verificou-se que as lâminas totais ótimas de irrigação foram sempre inferiores às lâminas para a máxima produtividade. Para este estudo, considerou-se um volume anual de água disponível de $66.644 .500 \mathrm{~m}^{3}$, que corresponde à capacidade máxima de oferta de água pelo projeto aos seus usuários. A disponibilidade anual de água constituiu uma restrição efetiva ao sistema de produção, apresentando um preço sombra (custo de oportunidade de se utilizar um determinado volume de água) de US\$281,60 por $1000 \mathrm{~m}^{3}$. Esse valor corresponde à redução esperada na função-objetivo (receita líquida do projeto) caso tal volume se torne mais restritivo em $1000 \mathrm{~m}^{3}$. Da mesma forma, o valor da receita líquida poderá aumentar em US\$281,60 para cada $1000 \mathrm{~m}^{3}$ adicionais de água. $\mathrm{O}$ intervalo de disponibilidade de água para o qual esse preço sombra é valido foi $48.579 .700 \mathrm{~m}^{3}$ a $82.819 .700 \mathrm{~m}^{3}$. Nesse intervalo, as atividades não são alteradas; entretanto podem se modificar os valores das áreas cultivadas. $\mathrm{O}$ preço sombra poderá representar o máximo valor que o usuário estará disposto a pagar, para ter disponível uma unidade adicional de água. Isso porque, em geral, um usuário pagará, no máximo, um valor igual à receita líquida gerada por uma unidade adicional do recurso.

\section{UMA VISÃO GERAL DA OTIMIZAÇÃO}

Os benefícios da irrigação ótima podem ser maiores para a sociedade como um todo do que para o irrigante individualmente. A sociedade pode estar preocupada com os objetivos mais amplos, assim como com a maximização da renda nacional, com a segurança alimentar ou com a minimização do uso dos recursos escassos ou dos impactos no meio ambiente. $\mathrm{O}$ fator mais limitante pode não ser o volume de água disponível, mas a qualidade química, física ou biológica da água que recebe carga de efluentes.

\section{Segurança alimentar}

O manejo convencional da água para irrigação é definido para maximizar a produção de alimentos por unidade de área. A maximização da produção total de alimentos pode ser uma preocupação mais importante e, considerando a disponibilidade de água limitada, pode-se representá-la pela seguinte função:

$$
\max Y_{\text {total }}=y(w) x
$$

sendo $\mathrm{Y}_{\text {total }}(\mathrm{kg})$ a produção total de alimentos, a partir de uma determinada quantidade de água, e x representa a área total irrigada, determinada pela disponibilidade total de água e pela lâmina de irrigação. Derivando a equação (73) em relação a w, igualando a zero, e re-arranjando os termos, encontra-se a equação de definição da máxima produção total de alimentos:

$$
\frac{\partial y(w)}{\partial w}=-\frac{1}{x} y(w) \frac{\partial x}{\partial w}
$$

sendo:

$$
\begin{aligned}
& x=\frac{V}{w} \\
& \frac{\partial x}{\partial w}=-\frac{V}{w^{2}}
\end{aligned}
$$

O inverso da área (1/x) e a produção $[y(w)]$ são positivos e diferentes de zero. Se a disponibilidade de água for restrita e se a economia de água ao se reduzir a lâmina de irrigação (w), é usada para irrigar áreas adicionais, a área $\mathrm{x}$ aumentará à medida que $\mathrm{w}$ diminui. Uma vez que a derivada de $\mathrm{x}$, em relação a $w$ é negativa e diferente de zero, o lado direito da equação (76) é positivo e diferente de zero. Desse modo, o lado esquerdo dessa equação tem que ser positivo e diferente de zero. Se a derivada de $\mathrm{y}(\mathrm{w})$ é positiva, o ponto de máxima produção total tem que estar na parte ascendente da curva de produção. Em resumo, a produção total ótima de alimentos, com quantidades limitadas de água, implica irrigações com lâminas inferiores à irrigação plena.

Para ilustrar o desenvolvimento de uma estratégia de maximização da produção

R. Bras. Agric. Irrigada, v.1, n.1, p.3-11, 2007. 
por unidade de água aplicada, será considerada a produção de feijão carioca (Figura 9). Nessa função, $w_{R}$ é a lâmina relativa de água, definida como:

$$
\mathrm{w}_{\mathrm{R}}=\frac{\mathrm{w}+\text { chuva }}{\mathrm{w}_{\mathrm{m}}}
$$

sendo w a lâmina de irrigação sazonal (mm) e $\mathrm{W}_{\mathrm{m}}$ a quantidade de água para a máxima produção $(600 \mathrm{~mm})$. Para essa região, a produtividade máxima tangível é $2.431,6 \mathrm{~kg}$ $\mathrm{ha}^{-1}$ com um volume de água esperado de $6.000 \mathrm{~m}^{3} \mathrm{ha}^{-1}$.

Das equações (73) e (75) tem-se:

$$
Y_{\text {total }}=y(w) \frac{V}{w}
$$

sendo $\mathrm{y}(\mathrm{w})$ a produtividade expressa em $\mathrm{kg}$ $\mathrm{ha}^{-1}, \mathrm{~V}$ o volume de água disponível $\left(\mathrm{m}^{3}\right)$ e $\mathrm{w}$ a quantidade de água aplicada $\left(\mathrm{m}^{3} \mathrm{ha}^{-1}\right)$.

$\mathrm{Na}$ Figura 10, a produção $\left(\mathrm{kg} \mathrm{m}^{-3}\right)$ está expressa em função da lâmina de água relativa $\left(w_{R}\right)$. Sob a irrigação plena $\left(w_{R}=1\right)$, a produção seria o máximo tangível de $2.431,6 \mathrm{~kg} \mathrm{ha}^{-1}$, ou $0,4053 \mathrm{~kg} \mathrm{~m}^{-3}$. À medida que $w_{R}$ é reduzida, a produção por $\mathrm{m}^{3}$ aumenta, alcançando um máximo de 0,5583 $\mathrm{kg} \mathrm{m}{ }^{-3}$, quando $\mathrm{w}_{\mathrm{R}}$ é $0,4483(44,83 \%$ da irrigação plena, ou $2.690 \mathrm{~m}^{3} \mathrm{ha}^{-1}$ ). No ponto ótimo, a produção por $\mathrm{m}^{3}$ de água aplicada representa um acréscimo de aproximadamente $37,8 \%$, em relação à produção obtida com a irrigação plena.

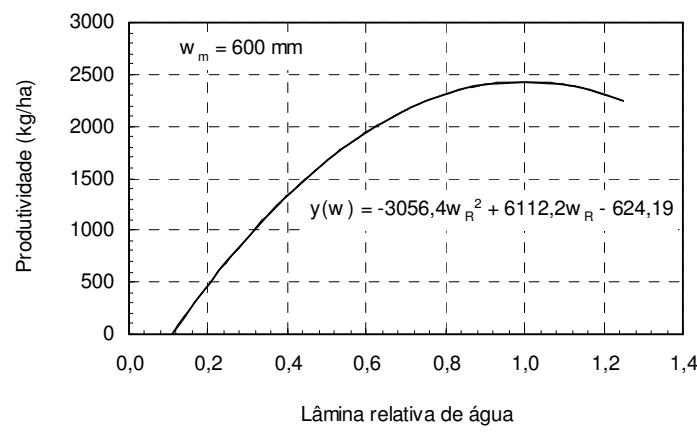

Figura 9 - Função de produção água-cultura, para o feijão carioca, obtida na região de Ilha Solteira, SP , adaptada de Frizzone (1986)

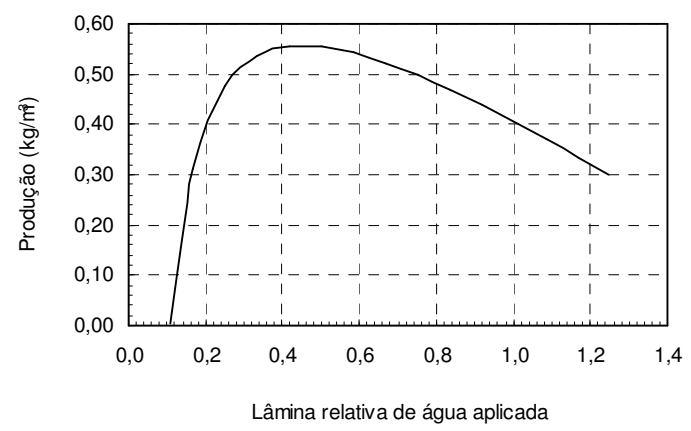

Figura 10 - Produção de feijão em $\mathrm{kg} \mathrm{m}^{-3}$ de água em função da lâmina relativa de água aplicada, na região de Ilha Solteira $(S P)$.

\section{Questões regionais e nacionais}

Objetivos regionais e nacionais podem ampliar os problemas de otimização e as restrições para a análise. Por exemplo, o desenvolvimento e a recuperação de projetos de irrigação para aumentar a produção de alimentos, e que envolvem investimentos com fundos do Banco Mundial, estipulandose que o empréstimo seja pago em moeda forte estrangeira: dada a alta instabilidade da moeda nacional, a moeda forte é um recurso severamente limitado. $\mathrm{O}$ critério essencial no planejamento da irrigação é, desse modo, maximizar a produção de alimentos por unidade de moeda forte.

Podem ser citados também os projetos de irrigação planejados para promover o assentamento de colonos, reduzindo a pressão demográfica urbana, para o qual o governo tem subsidiado novas áreas agrícolas, de modo a maximizar as chances de êxito econômico. A otimização, neste caso, envolve maximizar a área total de terras cultivadas, de modo consistente com um aceitável nível de lucratividade, enquanto se minimiza o risco aos produtores individuais, representando, portanto, um complexo conjunto de objetivos.

\section{Incerteza e risco}

A incerteza adiciona uma nova dimensão ao problema de otimização. Devido

R. Bras. Agric. Irrigada, v.1, n.1, p.24-49, 2007. 
aos efeitos imprevisíveis do clima, às doenças, aos solos e a vários outros fatores, as produtividades das culturas que serão alcançadas com uma determinada quantidade de água são incertas.

$\mathrm{Na}$ Figura 11, mostra-se a variabilidade nas produtividades de feijão, em experimentos conduzidos durante quatro anos (1988 a 1991), no CPAC-Embrapa (Figuerêdo et al., 1998). A função $\mathrm{y}(\mathrm{w})_{\mathrm{esp}}$ representa a função de produção esperada (produção média de todos os anos); $\mathrm{y}(\mathrm{w})_{\mathrm{pes}}$ representa a função pessimista (do ano em que ocorreu a menor produtividade) e $\mathrm{y}(\mathrm{w})_{\mathrm{otm}}$ representa a função otimista (do ano em que ocorreu a maior produtividade). Observa-se que, para uma mesma lâmina de água aplicada, por exemplo $500 \mathrm{~mm}$, a produtividade variou de $2.184,2 \mathrm{~kg} \mathrm{ha}^{-1}$ a $3.121,9 \mathrm{~kg} \mathrm{ha}^{-1}$, com valor esperado de $2.765,1 \mathrm{~kg} \quad \mathrm{ha}^{-1}$. Essa variabilidade exemplifica a incerteza da função de produção $\mathrm{y}(\mathrm{w})$.

$\mathrm{Na}$ Tabela 3, apresentam-se estratégias de irrigação, sob condição de restrição de água, para três cenários relativos à função de produção, considerando-se $\mathrm{p}=\mathrm{US} \$ 0,5 \mathrm{~kg}^{-1}$,

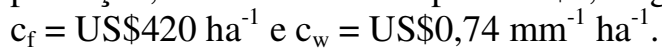

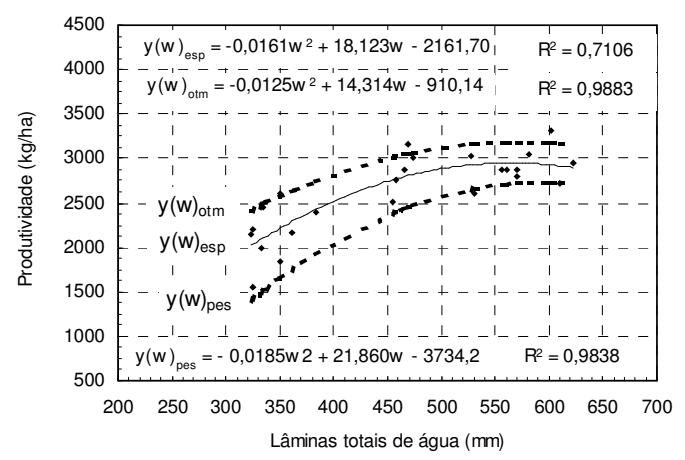

Figura 11 - Produtividades do feijoeiro, em função da lâmina de água aplicada durante o ciclo, obtidas em experimentos conduzidos por quatro anos no CPAC-Embrapa (Figuerêdo et al., 1998).

Observa-se que, se ocorrer a função otimista, a lâmina sazonal ótima é $374 \mathrm{~mm}$; se ocorrer a função esperada, é $431 \mathrm{~mm}$ e, se ocorrer a condição pessimista, é $488 \mathrm{~mm}$. O intervalo economicamente viável de irrigação também foi calculado para os três cenários, respectivamente: (245 $\mathrm{mm}$ a $573 \mathrm{~mm}),(337$ $\mathrm{mm}$ a $551 \mathrm{~mm})$ e $(416 \mathrm{~mm}$ a $572 \mathrm{~mm})$. Fica, assim, ressaltada a complexidade de se tomar decisão quanto à lâmina de irrigação, pela incerteza inerente à função de produção águacultura.

Na Figura 12, são apresentadas as curvas da receita líquida por $\mathrm{m}^{3}$ de água aplicada, para os três cenários analisados. Ao se considerar que ocorrerá a função de produção otimista, a decisão de aplicar uma lâmina de água de $245 \mathrm{~mm}$ poderá ser muito arriscada porque se ocorrer a função esperada, a receita líquida poderá ser praticamente nula e, se ocorrer o cenário pessimista, o prejuízo será inevitável. Uma decisão cuidadosa selecionaria uma lâmina de água que, embora não sendo a ótima, poderia satisfazer racionalmente aos três cenários, por exemplo, $416 \mathrm{~mm}$ ou um pouco maior, e ainda economizar água.

A complexidade da análise pode ser ainda maior porque, além da produtividade, os custos de produção $\left(\mathrm{c}_{\mathrm{f}}\right)$, os preços do produto (p) e os custos diretamente associados à água de irrigação $\left(\mathrm{c}_{\mathrm{w}}\right)$ são igualmente incertos. Uma análise baseada nesses valores seria, portanto, igualmente incerta. A relação entre receita líquida e produtividade, preço do produto e custos de produção continua sendo representada pela equação (17), mas as variáveis envolvidas nessa equação deverão ser tratadas como variáveis aleatórias. Cada variável deve ser tratada por uma apropriada distribuição de probabilidades e, por simulação, gerar valores aleatórios de $\mathrm{z}(\mathrm{w})$ para cada lâmina de irrigação pertencente a um intervalo de soluções economicamente viáveis. Os valores de $\mathrm{z}(\mathrm{w})$ deverão ser tratados também por uma distribuição de probabilidades e as decisões de irrigação poderão se basear na receita líquida esperada.

Para muitos administradores, a estratégia de irrigação escolhida será aquela que maximiza a receita líquida esperada. Mas Estratégias de irrigação que oferecem o maior retorno líquido esperado podem também estar associadas a um maior risco de perda, pois, se o plano ótimo aponta simultaneamente para a

R. Bras. Agric. Irrigada, v.1, n.1, p.3-11, 2007. 
redução da lâmina de irrigação e para o aumento da área irrigada, qualquer perda econômica poderá ser ampliada para a área.

Entre optar por uma estratégia de alto risco, com uma elevada expectativa de lucro, e por uma estratégia alternativa, com menor potencial de lucro, mas com menor probabilidade de perda, um produtor que apresenta aversão ao risco pode preferir esta última opção. A significância da aversão ao risco foi demonstrada por Frizzone et al. (2001), que usaram a teoria da árvore de decisão e da função utilidade para estudar a viabilidade da irrigação suplementar da canade-açúcar na região norte do estado de São Paulo. Um caso mais simples de análise de decisão pode ser feita, considerando-se apenas a incerteza na função de produção água-cultura (Figura 11). Utilizaram-se a distribuição triangular e o método de simulação de Monte Carlo para gerar $\mathrm{z}(\mathrm{w})$, utilizando-se as funções de produção aplicadas a 100 valores de lâminas de irrigação pertencentes ao intervalo de uso ótimo, apresentado na Tabela $3(245 \mathrm{~mm}$ a $572 \mathrm{~mm}$ ). Para cada lâmina de irrigação, foram calculadas as receitas líquidas $\mathrm{z}_{1}$ (valor pessimista), $z_{2}$ (valor otimista) e $z_{m}$ (valor médio) em US\$ $\mathrm{m}^{-3}$. Os valores de $\mathrm{z}(\mathrm{w})$ foram distribuídos em dez classes de frequiências, em que o ponto médio da classe constituía o valor representativo, e aplicou-se a distribuição triangular, obtendo-se a função de distribuição acumulada de $\mathrm{z}(\mathrm{w})$. Na Tabela 4, apresenta-se uma amostra da distribuição de frequiências, a média $E(z)$ e a variância $\operatorname{Var}(\mathrm{z})$.

Ao se observarem os valores de $\mathrm{E}(\mathrm{z})$ da Tabela 4, se o critério de seleção da melhor alternativa for $\mathrm{o}$ valor máximo esperado, então é preciso decidir pela aplicação da lâmina de $431 \mathrm{~mm}$, com E(z) = US\$ $0,11689 \mathrm{~m}^{-3}$. Uma decisão com $\mathrm{E}(\mathrm{z})$ muito próximo seria por $\mathrm{w}=416 \mathrm{~mm}$, porém com um nível de risco - medido pela variância de z - um pouco maior. Embora a máxima $\mathrm{E}(\mathrm{z})$ seja um critério usual para a tomada de decisão, os indivíduos têm diferentes graus de aversão ao risco. Assim, para um irrigante com disposição de assumir menor risco, a decisão seria por uma lâmina de $572 \mathrm{~mm}$, com menor $\mathrm{E}(\mathrm{z})$.

$\mathrm{Na}$ Figura 13, mostram-se E(z) e o risco correspondente medido em termos de desvio padrão, para as diferentes alternativas de irrigação. Observa-se que o uso de lâminas menores que $431 \mathrm{~mm}$ não é interessante porque elas proporcionam menores valores de $\mathrm{E}(\mathrm{z})$ associados a maiores níveis de risco. As decisões mais racionais deverão ser tomadas por lâminas de irrigação maiores ou iguais a $431 \mathrm{~mm}$.

Nesse caso, os irrigantes com maior aversão ao risco tenderão a utilizar lâminas de irrigação maiores. Observe que $572 \mathrm{~mm}$ é a lâmina de irrigação a oferecer o menor risco e a menor receita líquida por unidade de volume de água aplicada, porém. Essa lâmina corresponde à irrigação plena para as funções de produção otimista e pessimista e um excesso de água de $21 \mathrm{~mm}$, caso ocorra a função de produção esperada.

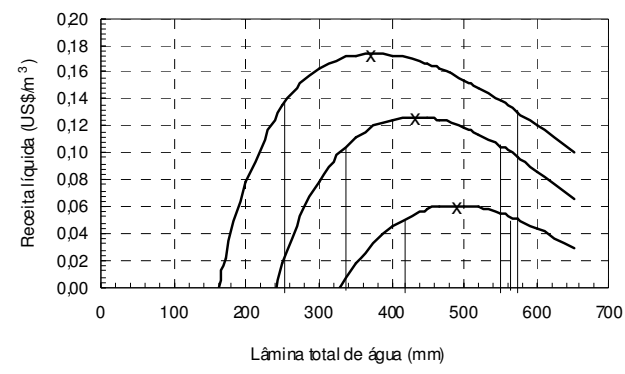

Figura 12 - Receitas líquidas para as estratégias de irrigação do feijoeiro, sob restrição de água, para os cenários otimista, esperado e pessimista, considerando-se $p=U S \$ 0,5 \mathrm{~kg}^{-1}, c_{f}=U S \$ 420 \mathrm{ha}$ ${ }^{1}$ e $c_{w}=U S \$ 0,74 \mathrm{~mm}^{-1} \mathrm{ha}^{-1}$

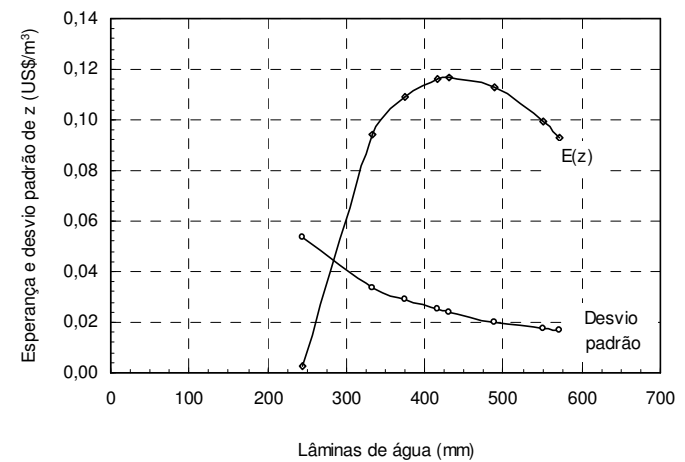

Figura 13 - Valores de E(z) e desvio padrão para diferentes decisões de uso de água. 
Tabela 3 - Estratégias de irrigação do feijoeiro sob restrição de água, para os três cenários apresentados $\left(\mathrm{p}=\mathrm{US} \$ 0,5 \mathrm{~kg}^{-1}\right.$, $c_{\mathrm{f}}=\mathrm{US} \$ 420 \mathrm{ha}^{-1} \mathrm{ec}_{\mathrm{w}}=\mathrm{US} \$ 0,74 \mathrm{~mm}^{-1} \mathrm{ha}^{-1}$ )

\begin{tabular}{|c|c|c|c|c|c|c|c|}
\hline \multirow{2}{*}{\multicolumn{2}{|c|}{$\begin{array}{l}\text { Uso de água } \\
(\mathrm{mm})\end{array}$}} & \multicolumn{2}{|c|}{ Função pessimista } & \multicolumn{2}{|c|}{ Função esperada } & \multicolumn{2}{|c|}{ Função otimista } \\
\hline & & \multirow{2}{*}{$\frac{\mathrm{kg} \mathrm{ha}^{-1}}{2267,4}$} & \multirow{2}{*}{$\frac{\mathrm{US} \$ \mathrm{~m}^{-3}}{0,0508}$} & \multirow[t]{2}{*}{$\mathrm{kg} \mathrm{ha}^{-1}$} & \multirow[t]{2}{*}{$\mathrm{US} \$ \mathrm{~m}^{-3}$} & \multirow[t]{2}{*}{$\mathrm{kg} \mathrm{ha}^{-1}$} & \multirow[t]{2}{*}{$\mathrm{US} \$ \mathrm{~m}^{-3}$} \\
\hline $\mathrm{w}_{\mathrm{m}}$ & $=572$ & & & & & & \\
\hline $\mathrm{w}^{*}$ & $=488$ & 2154,2 & 0,0607 & & & & \\
\hline $\mathrm{w}_{\mathrm{el}}$ & $=416$ & 1877,4 & 0,0508 & & & & \\
\hline $\mathrm{w}_{\mathrm{m}}$ & $=551$ & & & 2810,6 & 0,1050 & & \\
\hline $\mathrm{w}^{*}$ & $=431$ & & & 2570,0 & 0,1267 & & \\
\hline $\mathrm{w}_{\mathrm{el}}$ & $=337$ & & & 2045,6 & 0,1050 & & \\
\hline $\mathrm{W}_{\mathrm{m}}$ & $=573$ & & & & & 3187,7 & 0,1310 \\
\hline $\mathrm{w}^{*}$ & $=374$ & & & & & 2694,8 & 0,1740 \\
\hline $\mathrm{w}_{\mathrm{el}}$ & $=245$ & & & & & 1846,5 & 0,1310 \\
\hline
\end{tabular}

Tabela 4 - Probabilidades de $\mathrm{z}(\mathrm{w})$ para diferentes lâminas de irrigação, considerando-se $\mathrm{p}=\mathrm{US} \$ 0,5 \mathrm{~kg}^{-1}, \mathrm{c}_{\mathrm{f}}=\mathrm{US} \$ 420$ ha

\begin{tabular}{|c|c|c|c|c|c|c|c|}
\hline $\begin{array}{l}\text { Lâmina } \\
(\mathrm{mm})\end{array}$ & $\begin{array}{c}\mathrm{z}_{1} \\
\left(\mathrm{US} \$ \mathrm{~m}^{-3}\right) \\
\end{array}$ & $\begin{array}{c}\mathrm{z}_{\mathrm{m}} \\
\left(\mathrm{US} \$ \mathrm{~m}^{-3}\right) \\
\end{array}$ & $\begin{array}{c}\mathrm{z}_{2} \\
\left(\mathrm{US} \$ \mathrm{~m}^{-3}\right) \\
\end{array}$ & $\begin{array}{c}\mathrm{z}(\mathrm{w}) \\
\left(\mathrm{US} \$ \mathrm{~m}^{-3}\right)\end{array}$ & $\begin{array}{c}\text { Probabilidade } \\
(\%)\end{array}$ & $\begin{array}{c}\mathrm{E}(\mathrm{z}) \\
\left(\mathrm{US} \$ \mathrm{~m}^{-3}\right)\end{array}$ & $\operatorname{Var}(\mathrm{z})$ \\
\hline \multirow{10}{*}{374} & \multirow{10}{*}{0,03289} & \multirow{10}{*}{0,11949} & \multirow{10}{*}{0,17398} & 0,03994 & 1,629 & \multirow{10}{*}{0,10879} & \multirow{10}{*}{0,00084} \\
\hline & & & & 0,05405 & 4,888 & & \\
\hline & & & & 0,06816 & 8,146 & & \\
\hline & & & & 0,08227 & 11,405 & & \\
\hline & & & & 0,09638 & 14,663 & & \\
\hline & & & & 0,11049 & 17,921 & & \\
\hline & & & & 0,12460 & 18,045 & & \\
\hline & & & & 0,13871 & 12,946 & & \\
\hline & & & & 0,15282 & 7,768 & & \\
\hline & & & & 0,16693 & 2,589 & & \\
\hline \multirow{10}{*}{416} & \multirow{10}{*}{0,05070} & \multirow{10}{*}{0,1263} & \multirow{10}{*}{0,17140} & 0,05674 & 1,597 & \multirow{10}{*}{0,11613} & \multirow{10}{*}{0,00062} \\
\hline & & & & 0,06881 & 4,789 & & \\
\hline & & & & 0,09295 & 7,983 & & \\
\hline & & & & 0,09295 & 11,176 & & \\
\hline & & & & 0,10502 & 14,369 & & \\
\hline & & & & 0,11709 & 17,562 & & \\
\hline & & & & 0,12916 & 18,438 & & \\
\hline & & & & 0,14123 & 13,381 & & \\
\hline & & & & 0,15330 & 8,029 & & \\
\hline & & & & 0,16537 & 2,676 & & \\
\hline \multirow{10}{*}{431} & \multirow{10}{*}{0,05464} & \multirow{10}{*}{0,12671} & \multirow{10}{*}{0,16930} & 0,06037 & 1,591 & \multirow{10}{*}{0,11689} & \multirow{10}{*}{0,00056} \\
\hline & & & & 0,07184 & 4,773 & & \\
\hline & & & & 0,08331 & 7,955 & & \\
\hline & & & & 0,09477 & 11,137 & & \\
\hline & & & & 0,10624 & 14,319 & & \\
\hline & & & & 0,11770 & 17,500 & & \\
\hline & & & & 0,12917 & 18,496 & & \\
\hline & & & & 0,14064 & 13,461 & & \\
\hline & & & & 0,15210 & 8,077 & & \\
\hline & & & & 0,16357 & 2,692 & & \\
\hline \multirow{10}{*}{572} & \multirow{10}{*}{0,05077} & \multirow{10}{*}{0,09761} & \multirow{10}{*}{0,13121} & 0,05479 & 1,717 & \multirow{10}{*}{0,09320} & \multirow{10}{*}{0,00027} \\
\hline & & & & 0,06284 & 5,152 & & \\
\hline & & & & 0,07088 & 8,587 & & \\
\hline & & & & 0,07892 & 12,021 & & \\
\hline & & & & 0,08697 & 15,456 & & \\
\hline & & & & 0,09501 & 18,762 & & \\
\hline & & & & 0,10306 & 16,758 & & \\
\hline & & & & 0,11110 & 11,970 & & \\
\hline & & & & 0,11914 & 7,182 & & \\
\hline & & & & 0,12719 & 2,394 & & \\
\hline
\end{tabular}

R. Bras. Agric. Irrigada, v.1, n.1, p.3-11, 2007. 


\section{CONCLUSÕES}

É fundamental que ocorra uma mudança de paradigma no manejo da irrigação, revertendo-se o objetivo fisiológico de maximizar a produtividade para um novo objetivo econômico, que á a maximização da receita líquida proporcionada pela irrigação. Em termos simples, isso implica a otimização da irrigação. Esse novo enfoque é motivado pelo estreitamento nas margens de lucro dos agricultores, pela necessidade de minimizar os impactos ambientais oriundos da irrigação e pela competição pela utilização da água que, provavelmente, é a mais forte pressão.

A otimização da irrigação geralmente implica a redução da lâmina de água aplicada e da produção por unidade de área. Como os custos operacionais são reduzidos e a água está sendo disponibilizada para outros usos produtivos, os lucros da propriedade agrícola serão aumentados. Mesmo onde a reutilização da água é praticada, o manejo ótimo pode também beneficiar os produtores e outros usuários, devido ao reduzido custo de produção, pela economia de água e pela redução dos impactos ambientais.

Por uma perspectiva social, a irrigação ótima pode ser definida como a maximização dos benefícios totais, incluindo os benefícios não-monetários, como a proteção da qualidade da água, a segurança alimentar, a geração de empregos, a melhoria das condições sócio-econômicas das comunidades rurais e a fixação do homem no campo.

$O$ enfoque de otimização é um desafio maior do que a irrigação convencional praticada atualmente. No processo de planejamento da irrigação, necessita-se de incorporar funções de produção água-cultura e funções de custos detalhadas, que não são normalmente utilizadas no planejamento e no manejo convencional. A salinidade será, freqüentemente, um fator complicador na adoção da irrigação ótima, porque menor quantidade de água estará disponível para lixiviar os sais potencialmente danosos e, neste caso, poderá ocorrer um acúmulo de solutos em níveis restritivos à produção das culturas. Não sendo atendidas as necessidades de lixiviação em todos os pontos da área, a salinidade do solo aumentará onde a quantidade de água aplicada for menor que a evapotranspiração mais a demanda para lixiviação.

Por não ser a irrigação completamente uniforme, é preciso decidir-se pela aplicação de uma quantidade suficiente de água para compensar a desuniformidade e garantir a demanda de lixiviação em toda a área ou aceitar a redução na produtividade em parte da área. Avanços no manejo e na tecnologia de irrigação são necessários para enfocar a meta da demanda de lixiviação. A frequiência com que deve ser atendida a demanda de lixiviação é um ponto muito complexo e depende, além da tolerância da cultura à salinidade, da variação dessa tolerância ao longo do ciclo, da salinidade da água de irrigação, da precipitação efetiva e da drenagem do solo. De qualquer forma, a otimização da irrigação é um desafio entre cujos problemas está a salinidade.

No caso mais geral da otimização, os analistas terão que lidar com múltiplos objetivos e uma ampla gama de restrições e de estratégias alternativas, necessitando considerar a incerteza e a possibilidade de um maior risco financeiro. Essas análises são relativamente complexas e demandam modelos físicos sofisticados e ferramentas analíticas do domínio da pesquisa operacional.

Há mais de três décadas, já se desenvolvem modelos teóricos para otimizar a irrigação, mas muito pouco se tem pensado sobre a aplicação da otimização em nível operacional. Atualmente isso ainda é verdade, pois os princípios de otimização não estão sendo sistematicamente aplicados em condições de campo. Quando a água é limitante, os produtores têm desenvolvido, freqüentemente, estratégias de irrigação intuitivas e limitadas, para maximizar os benefícios pela água, mas têm feito isso sem os benefícios do rigor econômico, da engenharia e das análises científicas. 
Regras casuísticas, limitadas e imperfeitas, têm sido adotadas por alguns profissionais da agricultura para melhorar a eficiência econômica da irrigação. Essas regras são limitadas em espaço e inflexíveis para suportar as várias circunstâncias de uma propriedade agrícola, e podem conduzir a estratégias de irrigação que são subótimas. Por exemplo, Keller e Bliesner (1990) sugerem subirrigar $20 \%$, quando a água é limitada. Essa recomendação pode ser apropriada como uma primeira aproximação, mas não considera explicitamente os fatores econômicos e pode, desse modo, errar o nível ótimo por uma ampla margem. Uma confirmação desse fato está no trabalho de English e Raja (1996), que estimaram o nível ótimo de irrigação, em condições de água limitada, como estando entre $30 \%$ e $50 \%$ da irrigação plena para três conjuntos de circunstâncias muito diferentes (trigo em Columbia Basin, algodão na Califórnia, San Joaquin Valey, e milho no Saara Africano).

\section{REFERÊNCIAS BIBLIOGRÁFICAS}

\begin{abstract}
AMERICAN SOCIETY OF CIVIL ENGINEERS. Evapotranspiration and irrigation water requirements. New York, 1990. 465p. (Manual and Reports on Engineering Practice, 70).
\end{abstract}

ANDRADE JÚNIOR, A.S.; FRIZZONE, J.A.; BASTOS, E.A.; CARDOSO, M.J.; RODRIGUES, B.H.N. Estratégias ótimas de irrigação para a cultura da melancia. Pesquisa Agropecuária Brasileira, Brasília, v.36, n.2, p.301-305, 2001.

BERNARDO, S. Manual de irrigação. 6.ed. Viçosa: UFV, Imprensa Universitária, 1995. 657p.

BURTON, M.A.; KIVUMBI, D.; EL-ASKARI, K. Opportunities and constraints to improving irrigation water management: Foci for research. Agricultural Water Management, Amsterdam, v.40, n.1, p.37-44, 1999.

CALHEIROS, C.B.M.; QUEIROZ, J.E.; FRIZZONE, J.A; PESSOA, P.C.S. Estratégias ótimas de irrigação do feijoeiro: água como fator limitante da produção. Pesquisa Agropecuária Brasileira, Brasília, v.31, n.7, p.509-515, 1996.

R. Bras. Agric. Irrigada, v.1, n.1, p.3-11, 2007.
CUENCA, R.H. Irrigation systems design: an engineering approach. Englewood Cliffs: Prentice Hall, 1989. 551p.

DANTAS NETO, J.; AZEVEDO, C.A.V.; FRIZZONE, J.A. Uso da programação linear para estimar o padrão de cultura do perímetro irrigado Nilo Coelho. Revista Brasileira de Engenharia Agrícola e Ambiental, Campina Grande, v.1, n.1, p.9-12, 1997.

DOORENBOS, J.; KASSAN, A.H. Yield response to water. Rome: FAO, 1979. 193p. (Irrigation and Drainage Paper, 33).

DOORENBOS, J.; PRUITT, W.O. Guidelines for predicting crop water requeriments. Rome: FAO, 1977. 179p. (Irrigation and Drainage Paper, 24).

DUDLEY, N.J.; HOWELL, D.T; MUSGRAVE, W.J. Optimal intraseasonal irrigation water allocation. Water Resource Research, Washington, v.7, n.5, p.1051-1063, 1971.

English, M.J. Deficit irrigation. I: Analytical framework. Journal of Irrigation and Drainage Engineering, New York, v.116, n.3, p.399-412, 1990.

ENGLISH, M.J.; NAKAMURA, B.C. Effects of deficit irrigation and irrigation frequency on wheat yields. Journal of Irrigation and Drainage Engineering, New York, v.115, n.2, p.172-184, 1989.

ENGLISH, M.J.; NUSS, G.S. Designing for deficit irrigation. Journal of Irrigation and Drainage Engineering, New York, v.108, n.2, p.91-106, 1982.

ENGLISH, M.J.; SOLOMON, K.H.; HOFFMAN, G.J. A paradigm shift in irrigation management. Journal of Irrigation and Drainage Engineering, New York, v.128, n.5, p.267-277, 2002.

ENGLISH, M.J; RAJA, S.N. Perspectives on deficit irrigation. Agricultural Water Management, Amsterdam, v.32, p.1-14, 1996.

FIGUERÊDO, S.F.; FRIZZONE, J.A.; POZZEBON, E.J.; AZEVEDO, J.A.; GUERRA, A.F. Estabelecimento do momento de irrigação com base na tensão de água no solo para a cultura do feijoeiro. Engenharia Rural, v.9, n.2, p.35-49, 1998.

FRIZZONE, J.A. Funções de resposta do feijoeiro (Phaseolus vulgaris $\mathrm{L}$ ) ao uso de nitrogênio e lâmina de irrigação. 1986. 133p. Tese (Doutorado em Solos e Nutrição de Plantas) - Escola Superior de Agricultura "Luiz de Queiroz", Universidade de São Paulo, Piracicaba, 1986.

FRIZZONE, J.A. Aspectos econômicos da irrigação do feijão. Preços agrícolas, Piracicaba, n.105, p.6-7, 1995. 
FRIZZONE, J.A. Função de produção. In: Faria, M.A.; Silva. E.L.; Vilella, L.A.A.; Silva, A.M. (Ed.). Manejo da irrigação. Lavras: UFLA, Sociedade Brasileira de Engenharia Agrícola, 1998. p.86-116.

FRIZZONE, J.A.; Botrel, T.A.; Arce, R.A.B. Alocação de água e combinação de atividades pela programação linear em um projeto hidroagrícola no município de Guairá (SP). Scientia Agricola, Piracicaba, v.51, n.3, p.524-532, 1994.

FRIZZONE, J.A.; Matioli, C.S.; Rezende, R.; Gonçalves, A.C.A. Viabilidade econômica da irrigação suplementar da cana-de-açúcar, Saccharum spp., para a região Norte do Estado de São Paulo. Acta Scientiarum, Maringá, v.23, n.5, p.1131-1137, 2001.

FRIZZONE, J.A.; Teodoro, R.E.F.; Pereira, A.S.; Botrel, T.A. Lâminas de água e doses de nitrogênio na produção de forragem de aveia (Avena sativa L.). Scientia Agricola, Piracicaba, v.52, n.3; p.578-586, 1995.

GORANTIWAR, S.D.; SMOUT, I.K. Allocation of scarce water resources using deficit irrigation in rotational systems. Journal of Irrigation and Drainage Engineering. New York, v.129, n.3, p.155163, 2003.

HARGREAVES, G.H.; SAMANI, Z.A. Economics consideration of deficit irrigation. Journal of Irrigation and Drainage Engineering, New York, v.110, n.3, p.343-358, 1984.

HART, W.E.; NORUM, D.I.; PERI, G. Optimal seasonal applications analysis. Journal of the Irrigation and Drainage Division, New York, v.106, n.3, p.221-235, 1980.

HEINEMANN, A.B.; HOOGENBOOM, G.A.; GEORGIEV, G.A.; FARIA, R.T.; FRIZZONE, J.A. Center pivot irrigation management optimization of dry beans in humid areas. Transactions of the ASAE, St, Joseph, v.43, n.6, p.1507-15-16, 2000.

HEINEMANN, A.B.; SOUSA, S.A.V; FRIZZONE, J.A. Determinação da lâmina ótima de água para a cultura do milho doce na região de Sete Lagoas, MG. Revista Brasileira de Engenharia Agrícola e Ambiental. Campina Grande, v.5, n1, p.147-151, 2001.

JAMES, L.G. Principles of farm irrigation systems design. New York: John Wiley, 1988. 542p.

KELLER, J.; BLIESNER, R.D. Sprinkle and trickle irrigation. New York: Van Nostrand Reinhold, 1990. $651 \mathrm{p}$.

KUMAR, R.; KHEPAR, S.D. Decision models for optimal cropping patterns in irrigation based on crop water production functions. Agricultural Water Management, Amsterdam, v.3, n.1, p.65-76, 1980.

MATIOLI, C.S. Irrigação suplementar de cana-deaçúcar: modelo de decisão para o estado de São Paulo. 1998, 122p. Tese (Doutorado) - Escola Superior de Agricultura Luiz de Queiroz, Universidade de São Paulo, Piracicaba. 1998.

MARTIN, D.; BROCKLIN, J. VAN.; WILMES, G. Operating rules for deficit irrigation management. Transactions of the ASAE, St. Joseph, v.32, n.4, p.1207-1215, 1989.

McMILLAN JR., C. Mathematical programming: an introduction to the design and application of optimal decision machines. New York: John Wiley, 1970. 495p.

PAZ, V.P.S.; FRIZZONE, J.A.; BOTREL, T.A.; FOLEGATTI, M.V. Otimização do uso da água em sistemas de irrigação por aspersão. Revista Brasileira de Engenharia Agrícola e Ambiental, Campina Grande, v.6, n.3, p.404-408, 2002.

PHENE, C.J. Techniques for computerized irrigation management. Computer and Eletronics in Agriculture, New York, v.3, n.3, p.189-208, 1989.

QUEIROZ, J.E.; CALHEIROS, C.B.M.; PESSOA, P.C.S.; FRIZZONE, J.A. Estratégias ótimas de irrigação do feijoeiro: terra como fator limitante da produção. Pesquisa Agropecuária Brasileira, Brasília, v.31, n.1, p.55-61, 1996.

RODRIGUES, J.A.L.; COSTA, R.N.T.; FRIZZONE, J.A.; AGUIAR, J.V. Plano ótimo de cultivo no projeto de irrigação Morada Nova, Ceará, utilizando modelo de programação linear. Irriga, Botucatu, v.5, n.3, p.199$221,2000$.

SOUSA, S.A.V.; FRIZZONE, J.A.; PERES, F.C. Otimização da irrigação para diferentes déficits nas lâminas de água aplicadas às culturas. Engenharia Rural, Piracicaba, v.9, n.1, p.1-9, 1998.

STEWART, J.I; HAGAN, R.M.; PRUITT, W.O. Functions to predict optimal irrigation programs. Journal of the Irrigation and Drainage Division, New York, v.100, n.2, p.179-197, 1974.

VAUX JR.; PRUITT, W.O. Crop-water production functions. In: HILLEL, D., (Ed.). Advances in irrigation. New York: Academic Press, 1983. v.2, p.6197. 